\title{
Numerical analyses of a prefabricated retaining system for foundation pits in silt soils
}

\author{
Chengchao Guo \\ Associate Professor, School of Civil Engineering, Sun Yat-Sen University, \\ Guangzhou, China; Guangdong Provincial Key Laboratory of Oceanic Civil \\ Engineering, Guangzhou, China; Guangdong Provincial Research Center \\ for Underground Space Exploitation Technology, Guangzhou, China; \\ Southern Marine Science and Engineering Guangdong Laboratory (Zhuhai), \\ Zhuhai, China; Southern Engineering Inspection and Repair Technology \\ Research Institute, Guangzhou, China

\section{Ruisong Wang} \\ Graduate student, School of Civil Engineering, Sun Yat-Sen University, \\ Guangzhou, China; Guangdong Provincial Key Laboratory of Oceanic Civil \\ Engineering, Guangzhou, China; Guangdong Provincial Research Center \\ for Underground Space Exploitation Technology, Guangzhou, China; \\ Southern Marine Science and Engineering Guangdong Laboratory (Zhuhai), \\ Zhuhai, China
}

\begin{abstract}
Peiyuan Lin
Associate Professor, School of Civil Engineering, Sun Yat-Sen University, Guangzhou, China; Guangdong Provincial Key Laboratory of Oceanic Civil Engineering, Guangzhou, China; Guangdong Provincial Research Center for Underground Space Exploitation Technology, Guangzhou, China; Southern Marine Science and Engineering Guangdong Laboratory (Zhuhai), Zhuhai, China (Orcid:0000-0001-7648-6236) (corresponding author: linpy23@mail.sysu.edu.cn)

\section{Fuming Wang}

Professor, School of Civil Engineering, Sun Yat-Sen University, Guangzhou, China; Guangdong Provincial Key Laboratory of Oceanic Civil Engineering, Guangzhou, China; Guangdong Provincial Research Center for

Underground Space Exploitation Technology, Guangzhou, China; Southern Marine Science and Engineering Guangdong Laboratory (Zhuhai), Zhuhai, China; Southern Engineering Inspection and Repair Technology Research Institute, Guangzhou, China
\end{abstract}

This paper first introduces a new prefabricated recyclable retaining system that can be used to stabilise foundation pit excavation, particularly in urban areas. The new retaining system mainly consists of a steel frame, steel panels and bead polymer layers. A three-dimensional numerical model is built in Abaqus software to carry out numerical analyses on such a system that is used for a working shaft excavated in silts for a pipe-jacking project in Northern China. The model is first validated by comparing the analyses results against field monitoring data. After the validation, the model is further used to investigate the stresses and deformations of the main structural members of the new retaining system, including the $\mathrm{H}$-piles and steel panels. The ground surface settlement corresponding to the type of the retaining system is also studied. In addition, the influence of the thickness of steel panels and pile embedded ratio on the stresses and deformations of the panels and piles is examined. The retaining system introduced in this study is shown to have good potential to be used in the stabilisation of foundation pits in urban areas from the perspective of safety, fast construction, recyclable utilisation and reasonable cost.

Notatior
$c$
$D_{1}, D_{2}$
$E$
$E_{\mathrm{c}}$
$E_{\mathrm{FEM}}$
$E_{\mathrm{HW} 350}$
$e_{0}$
$H$
$H_{\mathrm{e}}$
$I_{\mathrm{FEM}}$
$I_{x}$
$I_{y}$
$K$
$k_{\delta}, k_{\sigma}$
$L$
$M$
$R$
$T$

cohesion of soil

distances from the foundation pit wall to the outer boundary of the model

Young's modulus

elastic modulus of 3/4 round C20 concrete piles elastic modulus of the finite-element method (FEM) pile

elastic modulus of HW350 steel piles void ratio height of structural members final excavation depth of the foundation pit area moment of inertia of the FEM pile area moment of inertia of an HW350 steel pile area moment of inertia of C20 concrete elastic bulk modulus slopes of the $\delta_{\mathrm{hm}}$ and $\sigma_{\mathrm{M}}$ curves, respectively length of structural members slope of the critical state line circumference of the working shaft thickness of steel panel $t$

$v$

W

Z

$\gamma$

$\gamma_{\text {crit }}$

$\Delta L$

$\Delta S$

$\Delta \delta_{1}-\Delta \delta_{4}$

$\Delta \delta_{\mathrm{hm}}$

$\delta_{\mathrm{h}}$

$\delta_{\mathrm{hm}}$

$\delta_{1}$

$\delta_{\mathrm{p}}$

$\delta_{\mathrm{p}^{\prime}}$

$\delta_{\mathrm{v}}$ spacing distance of the retaining pile

friction coefficient

width of structural members

vertical distance

soil unit weight

limiting shear slip

maximum ground settlement position between excavation stages 1 and 4

primary influence zone difference between the first stage of excavation and the final stage of excavation difference of the ground settlement with the excavation stage

difference value of the maximum horizontal displacement of retaining pile

horizontal displacement

maximum horizontal displacement

horizontal displacement of the steel panel from the initial position

horizontal displacement of the retaining pile real horizontal displacement of the steel panel ground surface settlement value 


$\begin{array}{ll}\delta_{\mathrm{vm}} & \begin{array}{l}\text { maximum ground surface settlement value } \\ \lambda\end{array} \\ \mu & \begin{array}{l}\text { slope of the normal compression line } \\ \sigma_{1}, \sigma_{2}, \sigma_{3}\end{array} \\ & \begin{array}{l}\text { first, second and third principal stresses, } \\ \text { respectively }\end{array} \\ \sigma_{\mathrm{M}} & \begin{array}{l}\text { von Mises stress } \\ \text { diameter of the pile hole }\end{array} \\ \phi & \text { soil friction angle }\end{array}$

\section{Introduction}

Massive construction of facilities and infrastructures has been initiated to meet the need for the rapid urbanisation in China. This has led to a wider utilisation of underground space in both urban and rural areas. In pipe-jacking and pipeline maintenance projects, it is usually necessary to excavate a small round or square foundation pit in order for the work to proceed. Here, the foundation pit is also referred to as a working shaft (Faustin et al., 2018; Wang et al., 2015; Zhang et al., 2016). High safety, fast construction, good sustainability and low cost are the goals of foundation pit construction. While traditional support systems such as row pile support, shotcrete support, reinforced concrete caisson support, pile anchor support and diaphragm walls have been widely used in the stabilisation of foundation pits (Chambers et al., 2016; Lam 2018; Qiu et al., 2016; Sun et al., 2015; Wang et al., 2018a; Wu et al., 2018), the main issues are the difficulties in subsequent repair and demolition work, given that for the working shaft, those retaining systems are typically used as temporary structures.

Recently, recyclable retaining systems have received much attention due to their environmentally friendly features and other competences as regards safety, construction and cost. Recyclable supporting structures, including Larssen sheet piles (Crawford and Byfield, 2002; Xie et al., 2014), steel truss retaining systems, prefabricated prestressed structures (Wang et al., 2015; Zhao et al., 2019), bioengineering retaining structures (Bella et al., 2017), H-beam piles with soil-mixing walls, cutter-soil-mixing walls (Arnold et al., 2011; Rabbani et al., 2019) and trench cutting remixing deep walls (Li et al., 2019), have been used in foundation pits. However, working shaft supporting systems such as steel sheet piles (Bilgin, 2012; Osthoff and Grabe, 2018) may not be appropriate due to inadequate rigidity, large deformation and high risk of leakage at joints. Other supporting structures mostly use cement materials and suffer disadvantages, including long periods of construction, difficulties in demolition and repairing cracks and leakages. Wang et al. (2018b, 2019a, 2019b, 2019c) introduced the bead polymer (BP) flexible waterproof technology (Wang et al., 2013) and the existing technology of steel structure to the traditional recyclable supporting system and proposed a new prefabricated retaining system. The proposed new system was proven to be cost-effective, construction time efficient, recyclable, reusable and, most importantly, safe.

Physical model tests and numerical simulations are two of the most often used methods for stability analysis of underground geotechnical structures. Physical model tests are usually conducted to study the destruction process of the underground geotechnical engineering, intuitively showing the physical-mechanical behaviours and deformation trends of the structure (Gao et al., 2019). Examples can be seen in foundation pits (Zhao et al., 2019), tunnelling (Gao et al., 2019; Li et al., 2017; Zhang et al., 2020a) and mining (Ju et al., 2017; Zhang et al., 2019). Numerical simulation methods are another common and effective tool for investigating the mechanical and deformation behaviours of underground structures - for example, finite-difference method (Gao et al., 2019), finite-element method (FEM) (Goh et al., 2017; Latapie et al., 2017; Likitlersuang et al., 2014; Pan et al., 2019; Zhang et al., 2015, 2020b; Zheng et al., 2014), boundary element method (Oliveira et al., 2019), finite-volume method (Ferziger and Peric, 2002), finite-discrete element method (Tran et al., 2015) and meshless method (Belytschko et al., 1996; Li and Liu, 2002). These numerical simulation methods are suitable for analysing stability problems, damage problems, prediction of the future structural behaviour, multi-field coupling problems and so on. Pan et al. (2019) established a three-dimensional (3D) finite-element (FE) model for a new retaining system used in the stabilisation of a circular foundation pit used as a warehouse for food storage. With a full-scale test for the new retaining system, they analysed the stress distributions in the retaining system and the ground settlement due to the excavation. Nevertheless, since this type of retaining system is relatively new, no numerical studies have been focused on its application in working shafts. The stability and optimisation design of the new prefabricated recyclable retaining system for working shaft requires further research.

In this study, the stresses and horizontal displacement of the retaining piles and steel panels at different excavation stages are numerically simulated based on a 3D FE model built in the Abaqus software platform. The numerical simulation model is then validated against the observed data of retaining piles in a working shaft project in Zhengzhou, Henan Province, China. The 3D FE model is proven able to reflect accurately the deformation behaviours of the structure and surrounding soils. Moreover, the influences of the embedded depth ratio (EDR) of H-piles and the thickness of steel panels on the deformations and stress distributions of the structure and ground settlement are examined. Here, the EDR is defined as the ratio of the embedded depth of an H-pile to the pile length. The results obtained in this study provide a reference for the use, optimisation design and maintenance of this type of retaining system.

\section{Basics of the new prefabricated retaining system}

Composition and process flow of the prefabricated recyclable retaining system

As shown in Figure 1, the new prefabricated recyclable retaining system has three main components - namely, steel frame, steel panel and BP. The steel frame consists of H-piles, crown beams and waist beams and serves as the primary supporting part of the 
system to sustain both static and dynamic loads under various conditions. Between H-piles are steel panels that are used to retain the excavated soils. Steel panels are structurally connected to $\mathrm{H}-$ piles. The BP is grouted between the steel panel and the soil, forming a flexible layer that buffers the transfer of the lateral earth pressure from soil to the steel panel. The buffering effectiveness depends on the rigidity and the thickness of the BP layer. In addition, the BP has been proved impermeable; thus, the BP layer also prevents seepage of the underground water from adjacent soils (Wang et al., 2013).

Figure 1 shows the typical construction procedure of the new prefabricated retaining system, which is described in detail in the following.

(a) Holes are drilled into the ground in the designated construction area ((a) in Figure 1). Holes and grooves must be strictly controlled, particularly the position of holes and the vertical accuracy of grooves.

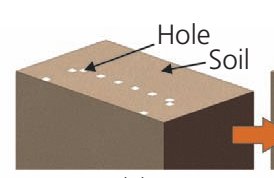

(a)

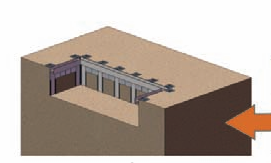

(f)

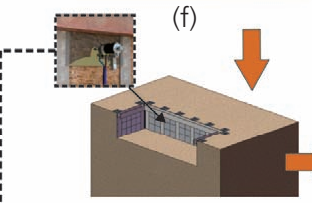

(g)

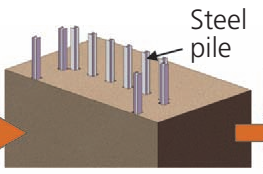

(b)

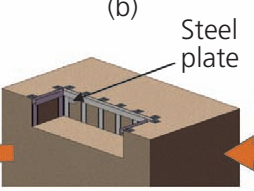

(e)

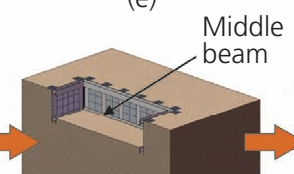

(h)
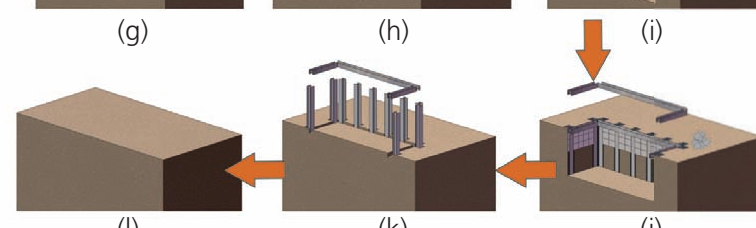

(I) (k)

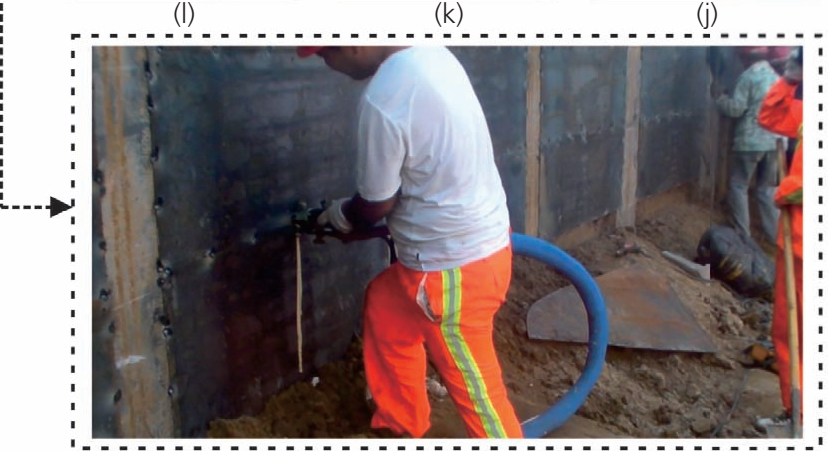

BP grout

Figure 1. Construction procedures for the new prefabricated recyclable retaining system (b) H-piles are then precisely placed into the holes ((b) in Figure 1). Then, the holes are filled with sand and gravel (or other appropriate materials) to maintain the stability of the holes and avoid hole collapse.

(c) The top of the H-piles are connected through a crown beam with high-strength bolts ((c) in Figure 1). Note that the mounting holes on the crown beam and the H-piles are formed before construction.

(d) The ground is excavated to a design elevation of a stage ((d) in Figure 1).

(e) As shown in (e)-(g) in Figure 1, steel panels are successively installed on the side-walls of the foundation pit within the depth of excavation. Bolts are used to fix them on the H-piles. After that, BP is injected to form an anti-seepage layer to prevent leakage.

$(f)$ Then, the waist beam is installed through bolt connections ((h) in Figure 1).

$(g)$ Steps $(d)-(f)$ are repeated until reaching the excavation depth of the prefabricated retaining system ((i) in Figure 1).

(h) All beams and steel panels are removed, and then the foundation pit is back-filled after completion of the project ((j)-(l) in Figure 1). The H-piles are pulled out using hydraulic pile extractor after the foundation pit is completely back-filled. As such, the components of the system are recycled.

\section{A case history}

The practical value of the new prefabricated retaining system was demonstrated in a pipe-jacking engineering project completed in Henan Province, China, as shown in Figure 2. The layout of the working shaft in bird's-eye view and cross-sectional view is shown in Figures 3(a) and 3(b), respectively. The working shaft is a rectangular well with a length of $7.85 \mathrm{~m}$ ( $X$ direction) and a width of $5.0 \mathrm{~m}$ ( $Y$ direction). The depth of excavation was $11.4 \mathrm{~m}$. The main components of the retaining system are the steel frame and steel panel; BP was not injected into the soil-steel panel interface to form an impermeable layer, as the groundwater table was not encountered within the excavation depth during the site geotechnical survey.

The length of the H-piles is $15.5 \mathrm{~m}$, resulting in a final EDR of $(15.5-11.4) / 15.5=0.265$. The pile spacing is $1.5 \mathrm{~m}$ in the $X$ direction and $2.3 \mathrm{~m}$ in the $Y$ direction. The steel panels were made of Q235 steel, the size and strength of which are defined in GB 50017-2017 (SAC, 2017). For example, the bending, shear, yield and ultimate tensile strengths of Q235 steel are 215, 125, 235 and $370 \mathrm{MPa}$, respectively. Bolts were used as connections among steel panels, H-piles and beams. The drill hole for H-piles has a $600 \mathrm{~mm}$ diameter. The material for back-fill is dry-mix-grade cement gravel. The H-pile, crown beam and waist beam were all made of HW350 steel with a strength grade of Q345 (GB 50017-2017 (SAC, 2017)), where the bending, shear, yield and ultimate tensile strengths are $305,175,345$ and $470 \mathrm{MPa}$, respectively. The bottom slab was made of $\mathrm{C} 30$ concrete with a thickness of $500 \mathrm{~mm}$. 

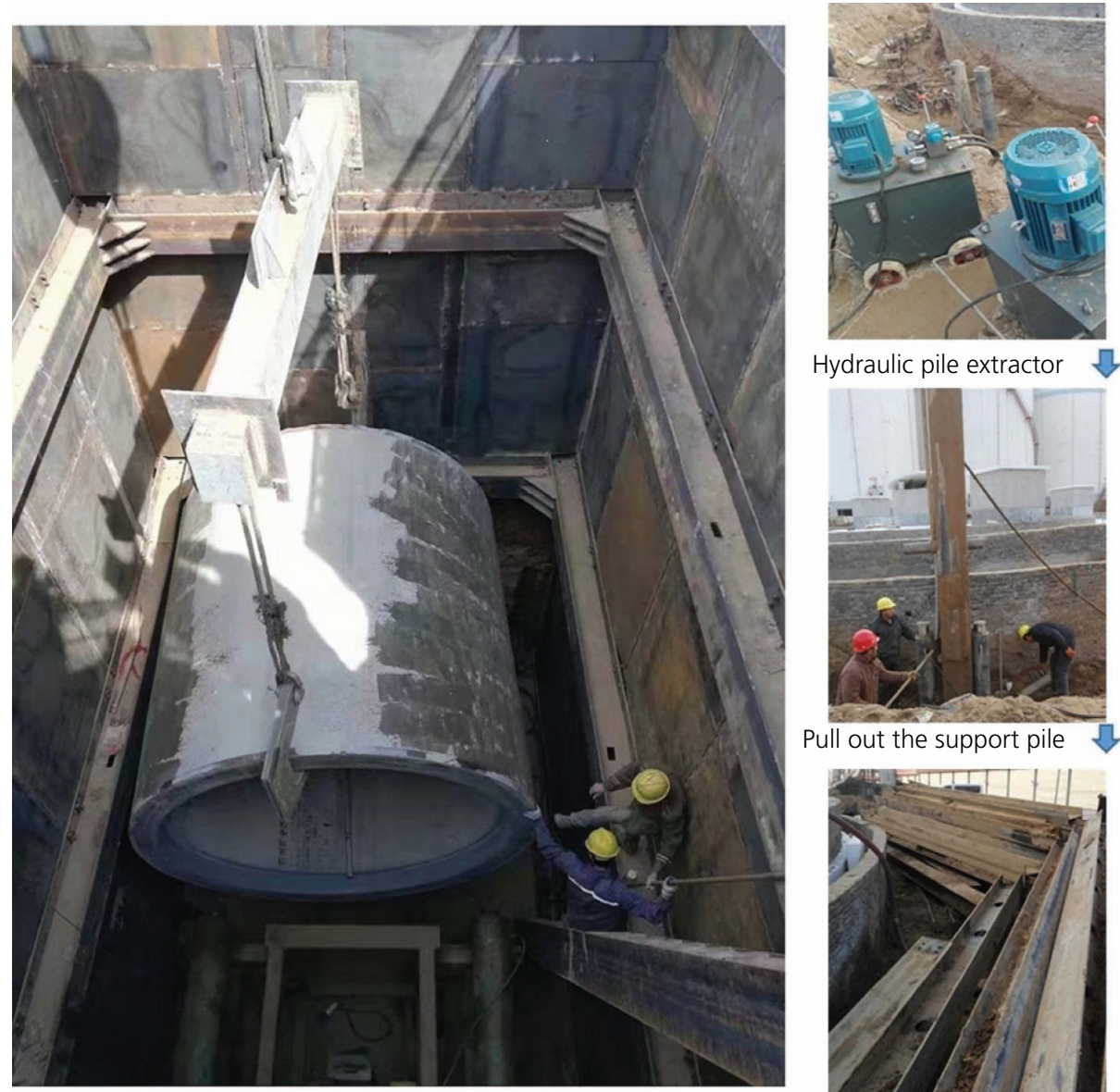

Pipe jacking in Niukouyu working shaft 4

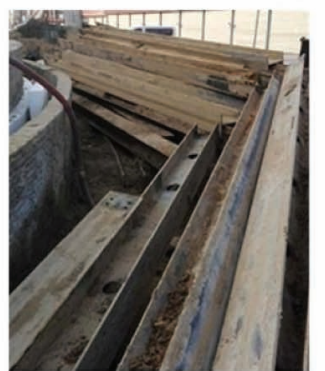

Recycled section steel support

Figure 2. Pipe jacking and recycling of the retaining system

The geotechnical investigation of the pipe-jacking site revealed that there are five soil layers within the entire excavation depth. From the ground surface top-down, the first layer is miscellaneous fill with a thickness of about $2.5 \mathrm{~m}$; the second layer is loess-like light silt with a thickness of about $3.6 \mathrm{~m}$; and the third layer is a $0.9 \mathrm{~m}$ thick loess-like medium silt, followed by another layer of $9.85 \mathrm{~m}$ thick light silt. The bottom layer is another medium silt with a thickness of about $1.2 \mathrm{~m}$. The layer information and soil shear strength parameters are summarised in Table 1.

\section{Three-dimensional FE model}

\section{Model description}

The FE model built is shown in Figure 4. The model dimensions were set to be 120,120 and $40 \mathrm{~m}$ for length, width and depth, respectively, to minimise the boundary effects on computation results. The soil, H-pile and concrete slab were modelled by the 3D solid eight-node integral element (C3D8), the steel panels were modelled by the four-node curved shell element (S4) and both the crown beam and waist beam were simulated by the linear Timoshenko beam element (B31).
Two constitutive models were assumed for the soils. One is the modified Cam Clay (MCC) model, and the other is the Mohr-Coulomb (MC) model. The parameters for the MCC model are initial void ratio $e_{0}$, slope of the normal compression line $\lambda$, elastic bulk modulus $K$, slope of the critical state line $M$ and Poisson's ratio $\mu$, while for the MC model, the parameters are elastic modulus $(E)$, Poisson's ratio $\mu$, soil friction angle $\phi$, soil cohesion $(c)$ and soil dilation angle $(\psi)$. These parameters are determined through laboratory triaxial shear tests and consolidation tests using the soil samples obtained from the construction site. Specifically, for MCC, $e_{0}=0.81, \lambda=0.0662$, $K=0.0042, M=1.414$ and $\mu=0.30$ (Du, 2017). For MC, $E$ ranges from 3 to $35 \mathrm{MPa}$ for different soil layers. The parameters for the MCC and MC models are shown in Table 1. Note that in this study, the soil dilation angle was taken as zero.

To simplify the modelling, the H-pile together with the drill hole is simplified into an equivalent rectangular pile using the equivalent stiffness method introduced by Liu and Hou (1998). The simplification is shown in Figure 5. The equivalent elastic modulus, $E_{\mathrm{FEM}}$, can be determined as 


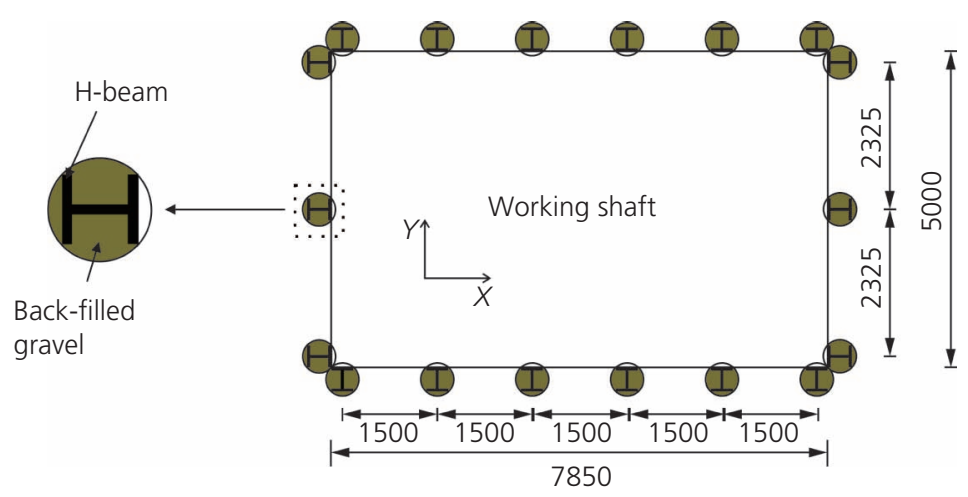

(a)

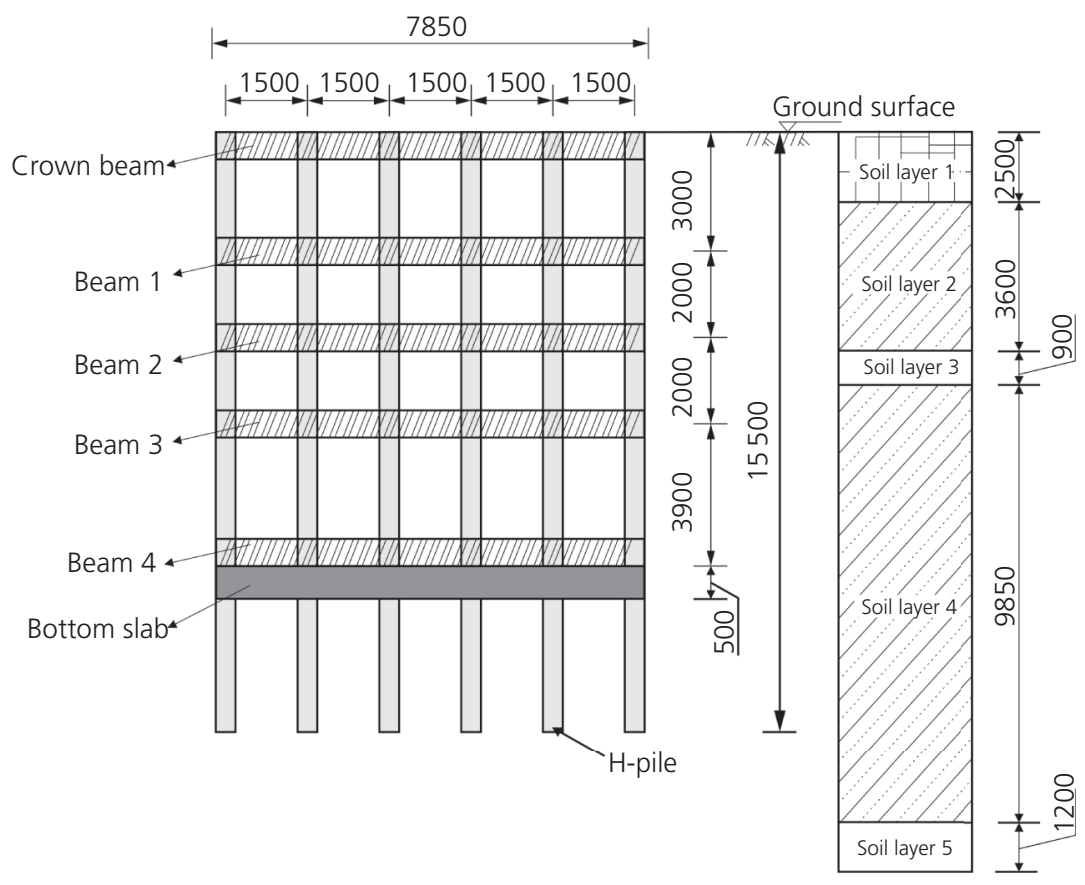

(b)

Figure 3. Layout of the working shaft: (a) bird's-eye view; (b) cross-sectional view (unit: mm)

Table 1. Summary of soil layer information and soil shear strength parameters

\begin{tabular}{|c|c|c|c|c|c|c|c|}
\hline $\begin{array}{l}\text { Soil } \\
\text { layer }\end{array}$ & Soil type & $\begin{array}{c}\text { Young's modulus, } \\
\text { E: MPa }\end{array}$ & $\begin{array}{c}\text { Thickness: } \\
\text { m }\end{array}$ & $\begin{array}{l}\text { Soil unit weight, } \\
\qquad \gamma: \mathrm{kN} / \mathrm{m}^{3}\end{array}$ & $\begin{array}{c}\text { Cohesion, } \\
\text { c: kPa }\end{array}$ & $\begin{array}{c}\text { Soil friction angle, } \\
\phi:^{\circ}\end{array}$ & $\begin{array}{c}\text { Poisson's } \\
\text { ratio, } \mu\end{array}$ \\
\hline 1 & Miscellaneous fill & 3 & 2.5 & 17.0 & 5.0 & 15.0 & 0.25 \\
\hline 2 & Loess-like light silt & 20 & 3.6 & 17.6 & 18.3 & 19.1 & 0.25 \\
\hline 3 & Loess-like medium silt & 35 & 0.9 & 17.7 & 22.0 & 21.7 & 0.25 \\
\hline 4 & Loess-like light silt & 20 & 9.85 & 17.6 & 17.8 & 23.4 & 0.25 \\
\hline 5 & Loess-like medium silt & 35 & 1.2 & 18.0 & 22.0 & 18.6 & 0.25 \\
\hline
\end{tabular}

1. $E_{\mathrm{FEM}}=\frac{\left(E_{\mathrm{c}} I_{y}+E_{\mathrm{HW} 350} I_{x}\right)}{I_{\mathrm{FEM}}}=\frac{\left(E_{\mathrm{c}} I_{y}+E_{\mathrm{HW} 350} I_{x}\right)}{a b^{3} / 12}$ where $a$ and $b$ are length and width, respectively, as defined in Figure 5. The parameter $I_{\mathrm{FEM}}=a b^{3} / 12$ is the area moment of inertia. The parameters $E_{\mathrm{HW} 350}$ and $I_{x}$ are the elastic modulus of the HW350 $\mathrm{H}$-pile and the area moment of inertia, respectively; they are $E_{\mathrm{HW} 350}$ 


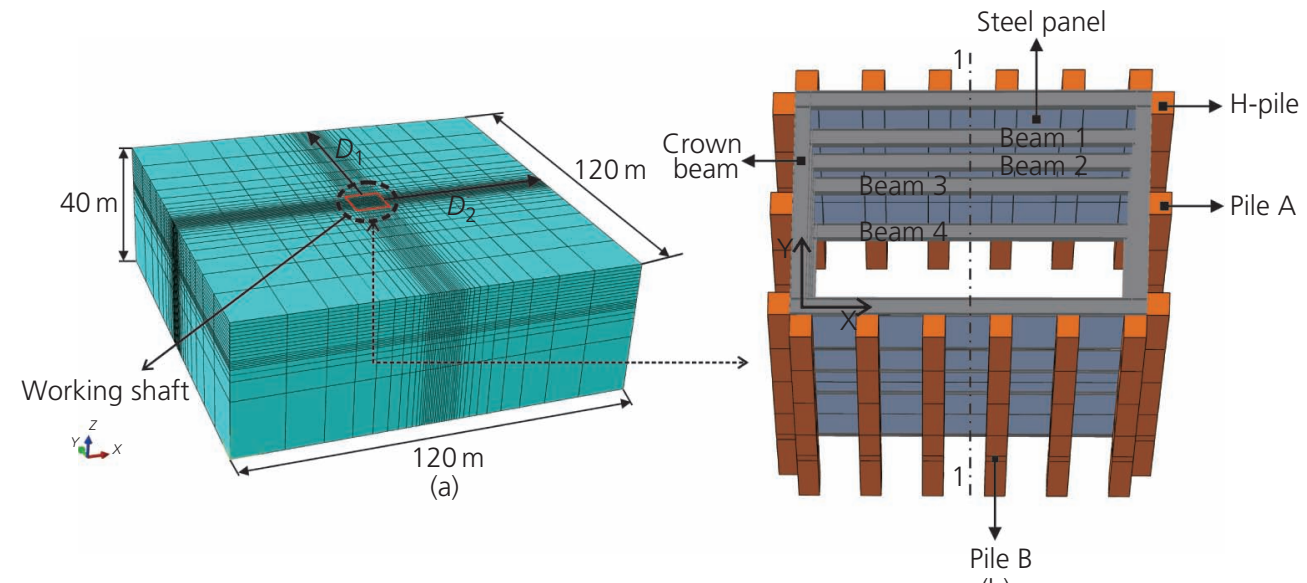

(b)

Figure 4. Three-dimensional FE model: (a) mesh of the global FE model; (b) the FE model of the retaining system

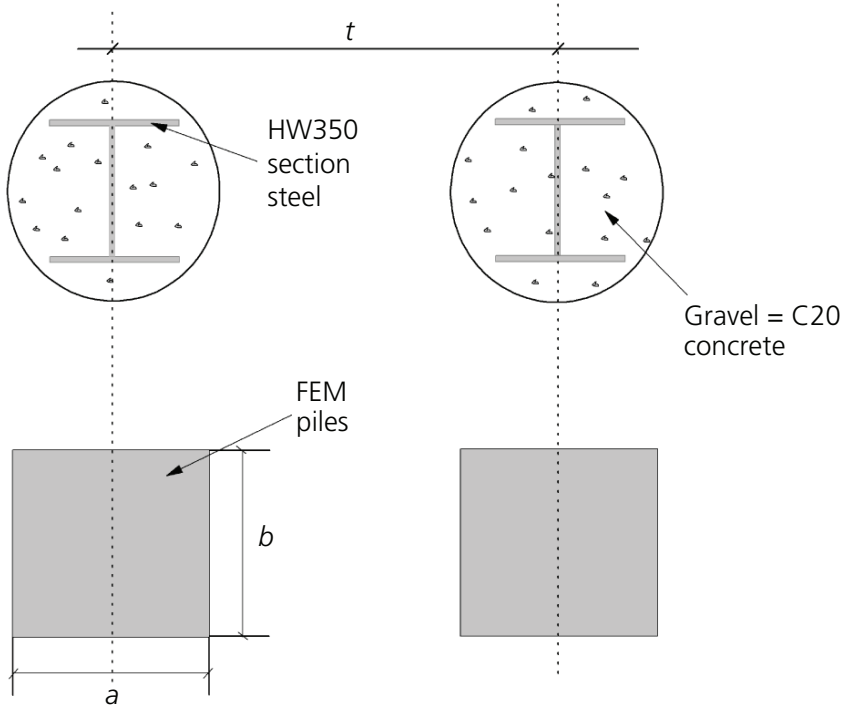

Figure 5. Simplification of the H-pile with the drill hole and backfills into an equivalent rectangular pile in the FE model using the equivalent stiffness method

$=210 \mathrm{GPa}$ and $I_{x}=4.214 \times 10^{-4} \mathrm{~m}^{4}$. Ignoring the effects of waist beams, the gravel that is filled outside the section steel pile is treated as $3 / 4$ round $\mathrm{C} 20$ concrete piles $(\Phi=600 \mathrm{~mm})$, its elastic modulus is $E_{\mathrm{c}}=30 \mathrm{GPa}$ and its area moment of inertia is $I_{y}=5.8 \times 10^{-3} \mathrm{~m}^{4}$. As a result, $E_{\mathrm{FEM}}$ is calculated to be $36.2 \mathrm{GPa}$. Other properties of the retaining structure are provided in Table 2.

\section{Contact and boundary conditions}

The structure-soil interface in Abaqus was a zero-thickness interface formed by duplicated nodes of structure and soil elements in contact. It can simulate both normal and tangential behaviours. This study used the friction contact; its behaviour is governed by a limiting shear slip $\left(\gamma_{\text {crit }}\right)$ and friction coefficient $(v)$, complying with the Coulomb frictional law. In this study, these two parameters are taken as $\gamma_{\text {crit }}=5 \mathrm{~mm}$ and $v=0.3$ (Zheng et al., 2014). The 'tie' constraint is used for the pile-soil interface at the pile end and the interfaces between structural members. For the boundary conditions, the ground surface is set to be free, the side boundaries are supported by rollers and the bottom of the soil is pinned.

\section{Steps of analysis}

In general, six steps are followed to carry out numerical analyses for the retaining system of the case history project. The details are described as follows, while the flow chart is provided in Figure 6. Note that these steps are exactly the same as the construction procedures executed in the case history.

Table 2. Properties of structural members

\begin{tabular}{|c|c|c|c|c|}
\hline Structural member & Section: $m$ & $\gamma: \mathrm{kN} / \mathrm{m}^{3}$ & E: MPa & $\mu$ \\
\hline Supporting pile & $L 0.5 \times W 0.5 \times H 15.0$ & 32.5 & $36.2 \times 10^{3}$ & 0.25 \\
\hline Steel panel 1 & $T 000.3 \times W 3.0 \times L 8.0$ & 78.0 & $210 \times 10^{3}$ & 0.30 \\
\hline Steel panel 2 & $T 000.3 \times W 2.0 \times L 5.0$ & 78.0 & $210 \times 10^{3}$ & 0.30 \\
\hline Steel panel 3 & $T 000.3 \times W 3.0 \times L 8.0$ & 78.0 & $210 \times 10^{3}$ & 0.30 \\
\hline Steel panel 4 & $T 000.3 \times W 2.0 \times L 5.0$ & 78.0 & $210 \times 10^{3}$ & 0.30 \\
\hline Beam & HW350 section steel & 78.0 & $210 \times 10^{3}$ & 0.30 \\
\hline C30 bottom slab & $L 0.5 \times W 0.5 \times H 0.5$ & 25.0 & $30 \times 10^{3}$ & 0.20 \\
\hline
\end{tabular}

$H$, height; $L$, length; $T$, thickness; $W$, width 


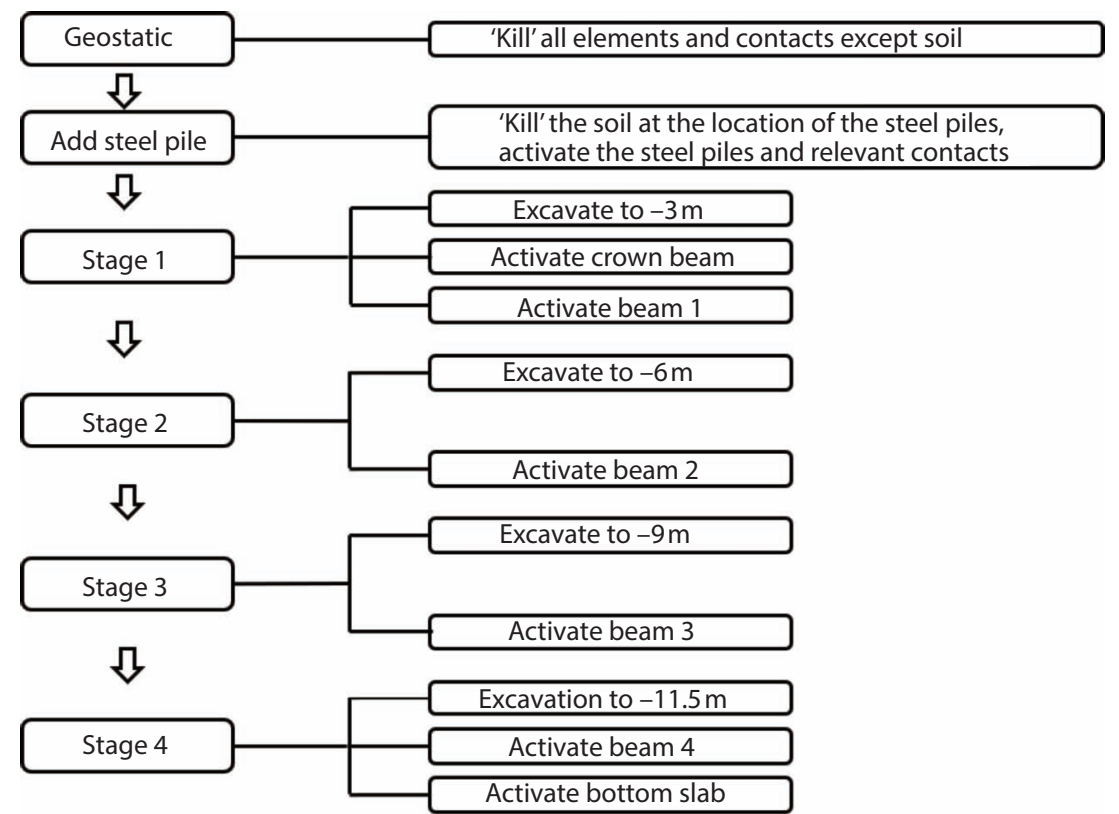

Figure 6. Flow chart summarising the steps for carrying out analyses

Step 1. Geostatic equilibrium. This is performed to reach an equilibrium state at initial conditions.

Step 2. Add H-piles. In this step, soils at the locations of those Hpiles are 'killed' and then the H-piles and related contacts are activated.

Step 3. Stage 1 excavation. The ground is first excavated to an elevation of $-3 \mathrm{~m}$, given that the elevation of the ground surface is $0 \mathrm{~m}$. Then, the crown beam is activated, followed by activation of beam 1 .

Step 4. Stage 2 excavation. The excavation is continued until reaching an elevation of $-6 \mathrm{~m}$; after that, beam 2 is activated.

Step 5. Stage 3 excavation. After reaching an elevation of $-9 \mathrm{~m}$, beam 3 is activated.

Step 6. Stage 4 excavation and completion. The excavation is continued to an elevation of $-11.5 \mathrm{~m}$, then beam 4 is activated and, lastly, the bottom concrete slab is activated.

\section{Validation of the FE model}

For this project, the horizontal displacement of pile B (see Figure 4) was recorded using an inclinometer, which was fixed on the tension side of the pile, and displacement data were collected at intervals of $0.5 \mathrm{~m}$ along the depth. In the FE model (Figure 7), the monitoring points were set to be at the same locations of those monitored in the project. Note that in the FE model, both displacement and stress are recorded.

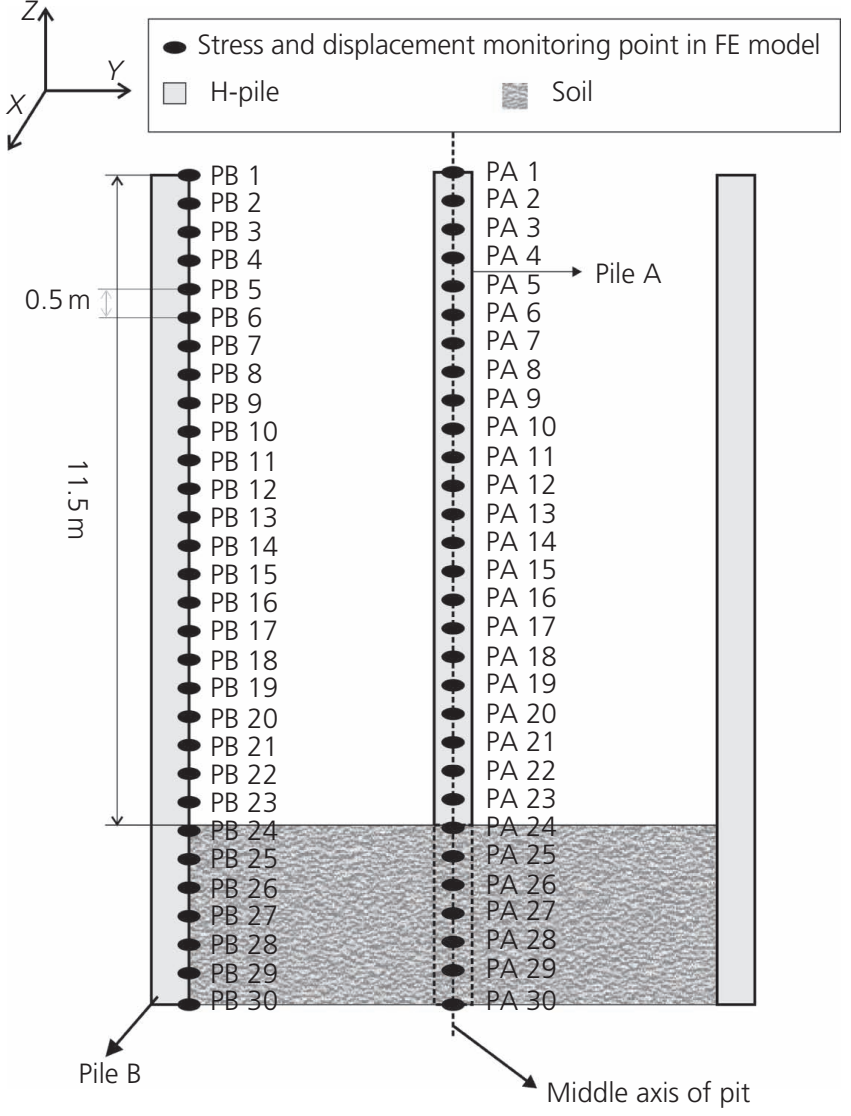

Figure 7. Layout of the monitoring points in FE model for the pile behaviour in section 1-1 
Piles A and B, as defined in Figure 4, are selected for stability analyses, as they are expected to have maximum horizontal displacements in the $X$ and $Y$ directions, respectively. As shown in Figure 7, points from PA 1 to PA 30 and from PB 1 to PB 30 on the tension side of the piles are used in the FE model to monitor the von Mises stress $\left(\sigma_{\mathrm{M}}\right)$ and horizontal displacement $\left(\delta_{\mathrm{h}}\right)$ of the retaining pile at different depths and at different excavation stages.

Figure 8(a) shows the horizontal displacement of pile B at completion of the foundation pit excavation along the depth. The first observation is that, in general, the horizontal displacements $\delta_{\mathrm{h}}$ by both FE models appear first to increase with depth until about $Z=9 \mathrm{~m}$, where the maximum $\delta_{\mathrm{h}}$ values are reached, and then $\delta_{\mathrm{h}}$ decreases. This type of pile deformation trend is similar to that of braced walls (Clough and O'Rourke, 1990). The maximum $\delta_{\mathrm{h}}$ by the MCC FE model is $3.4 \mathrm{~mm}$, which is only about half of that by the MC FE model (i.e. $6.4 \mathrm{~mm}$ ). The second observation is that the calculated results using the MCC FE model are in good agreement with the observed data, while in this case study, the MC FE model seems to fail to capture the trend. The measured maximum $\delta_{\mathrm{h}}$ is $3.0 \mathrm{~mm}$, which is very close to the prediction by the MCC FE model.

The ground surface settlement $\delta_{\mathrm{v}}$ is shown in Figure $8(\mathrm{~b})$. The $X$-axis ' $D_{1}$ ' represents the distance from the foundation pit wall to the outer boundary of the model. It is found that the $\delta_{\mathrm{v}}$ by the MC FE model is positive, meaning that the ground surface heaves. Although this is possible in other case histories (Grande, 1998), it does not match observations for the case study under analysis. On the other hand, the $\delta_{\mathrm{v}}$ by the MCC FE model is negative, indicating that the ground surface settles, which is consistent with the site observations. Therefore, in this case, the MCC constitutive model is superior to the MC constitutive model. This can be expected as hardening elastic-plastic constitutive models (e.g. MCC) usually give more reasonable surface settlement predictions behind the wall than elastic-ideal plastic constitutive models do (Potts and Zdravkovic, 2001). Based on the above analyses, the MCC FE model is utilised to carry out further analyses for the retaining system of interest.

\section{Analysis results}

As the FE model is validated in the previous section, it is now used to investigate the stresses and displacements that the piles and steel panels bear. Also, the ground settlement adjacent to the wall is examined.

\section{Stresses and horizontal displacements of H-piles}

Figures 9(a)-9(d) present the contours of the von Mises stress $\left(\sigma_{\mathrm{M}}\right)$ and horizontal displacement $\left(\delta_{\mathrm{h}}\right)$ of piles A and B. Here, $\sigma_{\mathrm{M}}$ is an equivalent stress defined by Chen and Sarip (2005) as

2. $\sigma_{\mathrm{M}}=\sqrt{\frac{\left(\sigma_{1}-\sigma_{2}\right)^{2}+\left(\sigma_{2}-\sigma_{3}\right)^{2}+\left(\sigma_{3}-\sigma_{1}\right)^{2}}{2}}$

where $\sigma_{1}, \sigma_{2}$ and $\sigma_{3}$ refer to the first, second and third principal stresses, respectively.

The contour maps clearly show that piles A and B have the largest $\sigma_{\mathrm{M}}$ and $\delta_{\mathrm{h}}$ in the $X$ and $Y$ directions, respectively. Therefore, these two piles are selected for further analyses.

Figures 10(a)-10(f) present the von Mises stress $\sigma_{\mathrm{M}}$, bending moment $(\mathrm{SM})$ and horizontal displacement $\left(\delta_{\mathrm{h}}\right)$ of pile A and pile B. After the first stage of excavation - that is, excavation stage 1 - the maximum $\sigma_{\mathrm{M}}$ of pile A occurs at $Z=2.8 \mathrm{~m}$, whereas the maximum $\sigma_{\mathrm{M}}$ of pile $\mathrm{B}$ locates at top of the pile. This is mainly due to the fact that pile A and pile B have different modes of movement, which will be explained in detail in the next section. As excavation proceeds, the location of the maximum $\sigma_{\mathrm{M}}$ gradually moves deeper, and the magnitude becomes larger. After the final stage of excavation - that is, excavation stage 4 - the maximum $\sigma_{\mathrm{M}}$ of both piles $\mathrm{A}$ and $\mathrm{B}$ stays at about $Z=9.0 \mathrm{~m}$ and

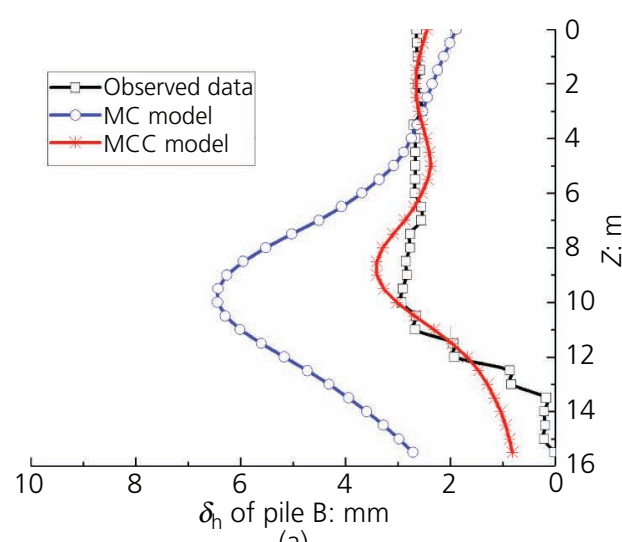

(a)

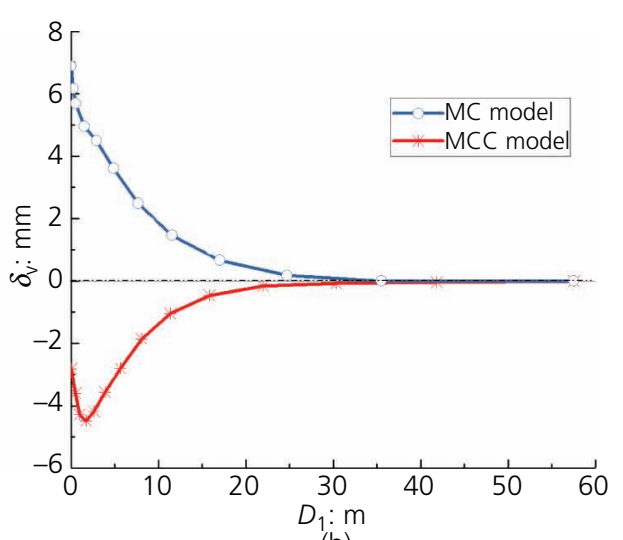

(b)

Figure 8. Comparisons of calculated against observed data: (a) horizontal displacement of pile $B$; (b) settlement of the ground surface along $D_{1}$ 


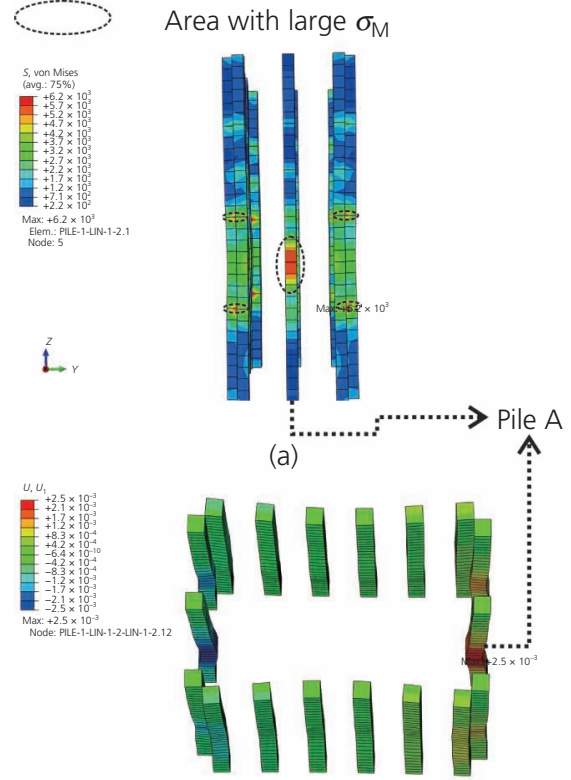

(c)

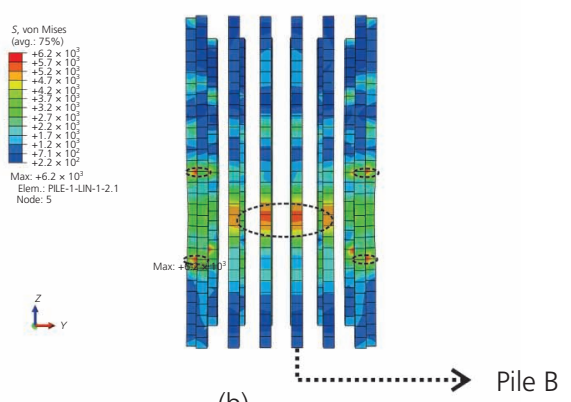

(b)

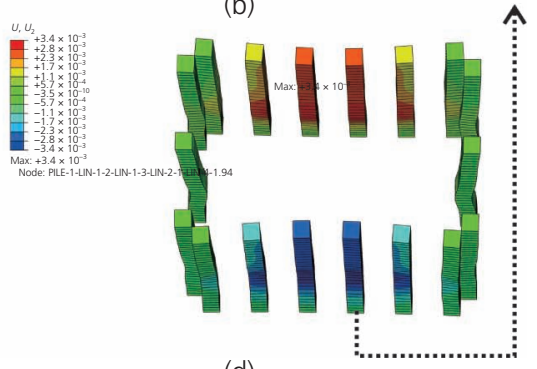

(d)

Figure 9. Contours of von Mises stress and horizontal displacement of retaining piles: (a) $\sigma_{\mathrm{M}}$ of piles on the $Y-Z$ plane; (b) $\sigma_{\mathrm{M}}$ of piles on the $X-Z$ plane; (c) $\delta_{\mathrm{h}}$ of retaining piles along the $Y$ direction; (d) $\delta_{\mathrm{h}}$ of retaining piles along the $X$ direction

the maximum $\sigma_{\mathrm{M}}$ is about $5.8 \mathrm{MPa}$ for pile $\mathrm{A}$ and $5.4 \mathrm{MPa}$ for pile B. The difference is insignificant. Note that the design tensile strength for the grade Q345 H-beam is $305 \mathrm{MPa}$, which is about two orders larger than the calculated maximum $\sigma_{\mathrm{M}}$. This suggests that the retaining system investigated here is extremely conservative. One may argue that such an overdesign would cost much more than needed. However, the authors argue that as the retaining system is prefabricated and can be recycled and reused in many other projects, the average cost is indeed much lower and the system itself is cost-effective, as well as delivering other benefits such as low environmental impacts.

The bending moments of pile A and pile B along depths are similar to each other in general, although the bending moment of pile $A$ is found to be slightly higher than that of pile $B$, as shown in Figures 10(c) and 10(d). This is because the spacing for pile A is slightly larger than that for pile B. For both piles, the maximum bending moments are found to be about $5 \mathrm{kN} \mathrm{m}$ and located at $1.5 \mathrm{~m}$ after completion of the first excavation stage. The maximum bending moment increases as excavation proceeds and the location moves downwards. Meanwhile, as waist beams are installed and start to play a bracing role in restricting the horizontal displacement of the pile, the bending moment of the pile gradually decreases at the position where it is connected to the beams and finally reaches a negative bending moment. This indicates a state transition from tension to compression. Due to the impact of the pipe-jacking construction, no waist beams are to be installed at a depth of 7-11 $\mathrm{m}$ of the working shaft. Hence, the bending moment beyond this depth range gradually increases with the foundation pit excavation. At completion of excavation stage
4, the maximum bending moment reaches $40 \mathrm{kN}$ m for both piles. The bending moment curve appears to be bidirectional, which is consistent with previous studies reported in the literature (e.g. Pan et al., 2019). For HW350 steel H-piles, the allowable stress is $315 \mathrm{MPa}$ and the bending cross-sectional coefficient is $2300 \mathrm{~cm}^{3}$ (Pan et al., 2019), resulting in an allowable bending moment of $315 \mathrm{MPa} \times 2300 \mathrm{~cm}^{3}=724.5 \mathrm{kN} \mathrm{m}$. Again, this is over two orders larger than the computed maximum bending moment of the piles (i.e. $40 \mathrm{kN} \mathrm{m}$ ), and the piles are very safe from the perspective of flexure failure.

Figures $10(\mathrm{e})$ and $10(\mathrm{f})$ show the distributions of $\delta_{\mathrm{h}}$ for pile A and pile $\mathrm{B}$ along the depth with respect to different excavation stages. After the first stage of excavation, due to the upper levels of support not being preloaded, pile B deformed as a cantilever, and the $\delta_{\mathrm{h}}$ at the top of pile $\mathrm{B}$ is found to be $1.6 \mathrm{~mm}$. On the other hand, due to the geometry effects of the foundation pit (e.g. soil arching effects), displacements of the supporting members along the long side ( $X$ direction in this case) are generally much larger than those along the short side ( $Y$ direction in this case). With the deflection of the waist beam in the $X$ direction, the waist beam in the $Y$ direction has a movement tendency against the displacement of pile A. As a result, the $\delta_{\mathrm{h}}$ at the top of pile A is just $0.2 \mathrm{~mm}$. As the excavation proceeds, lateral displacement of the piles in the upper portion is restrained by installation of new supporting members, while for the lower part, it deforms more due to the lack of waist beams (Goh et al., 2017). After the final excavation stage, the maximum $\delta_{\mathrm{h}}$ is $2.5 \mathrm{~mm}$ for pile A and $3.5 \mathrm{~mm}$ for pile B; both appear at about $9 \mathrm{~m}$. The piles deformed as a convex shape, which is consistent with the analysis outcomes by Clough 
Geotechnical Research

Volume 7 Issue 3
Numerical analyses of a prefabricated

retaining system for foundation pits in

silt soils

Guo, Wang, Lin and Wang

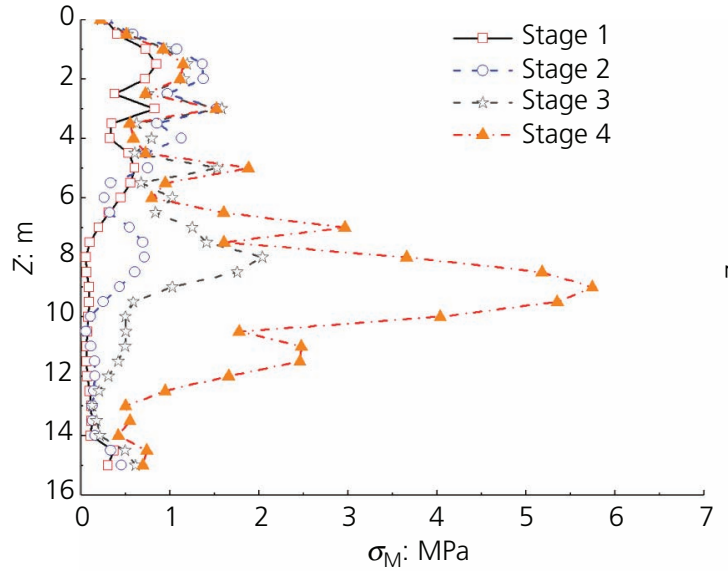

(a)

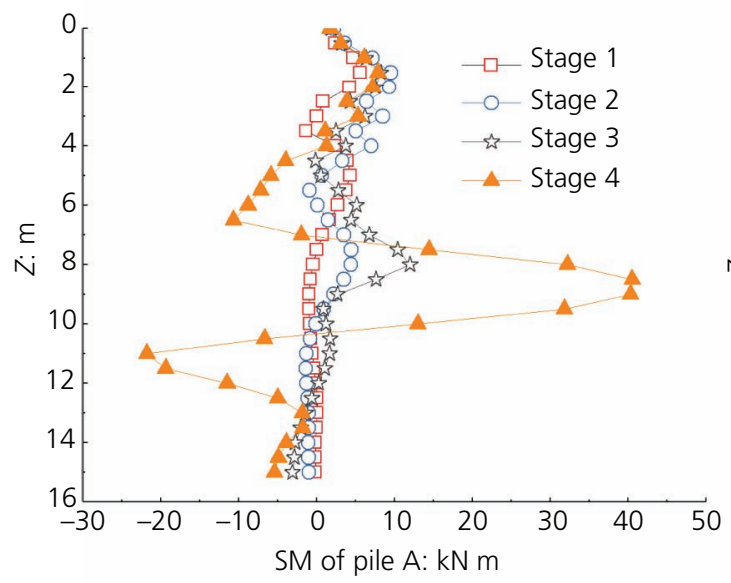

(c)

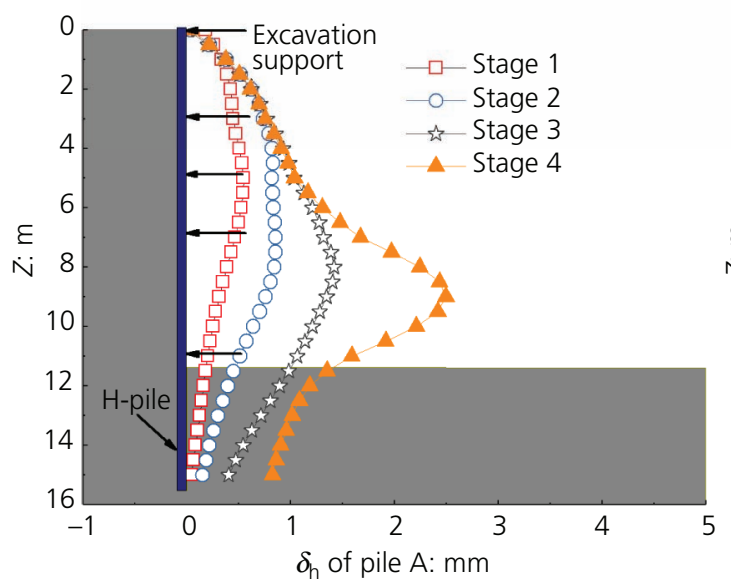

(e)

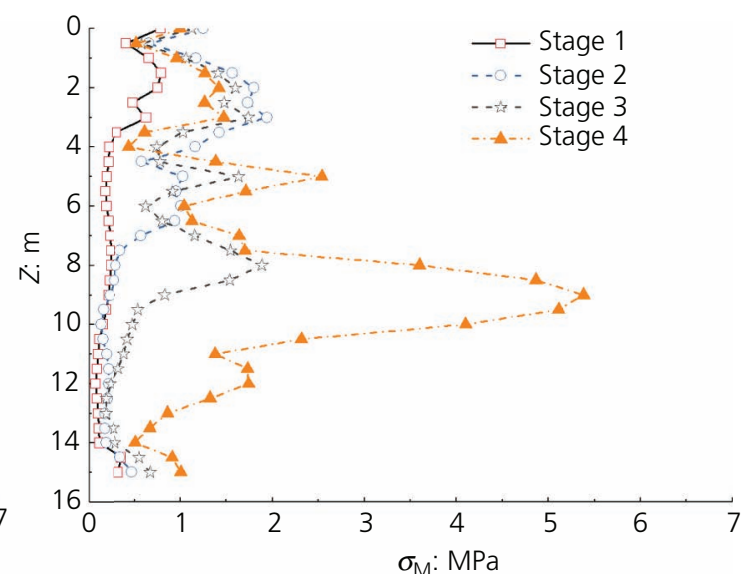

(b)

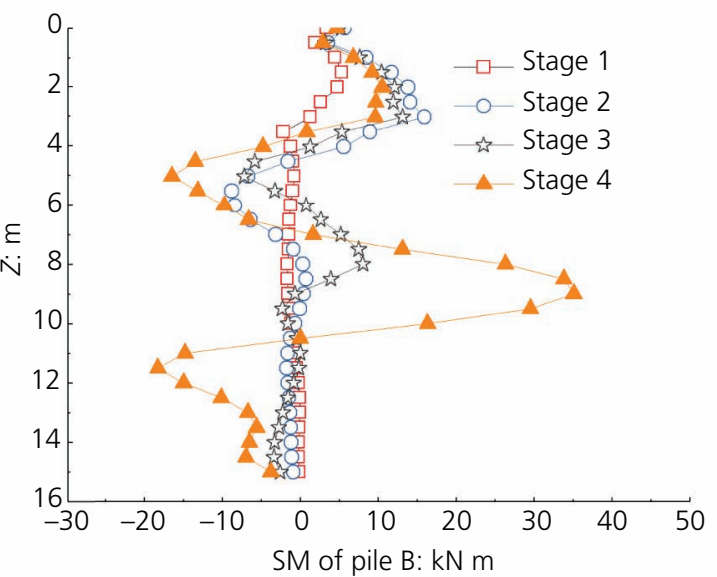

(d)

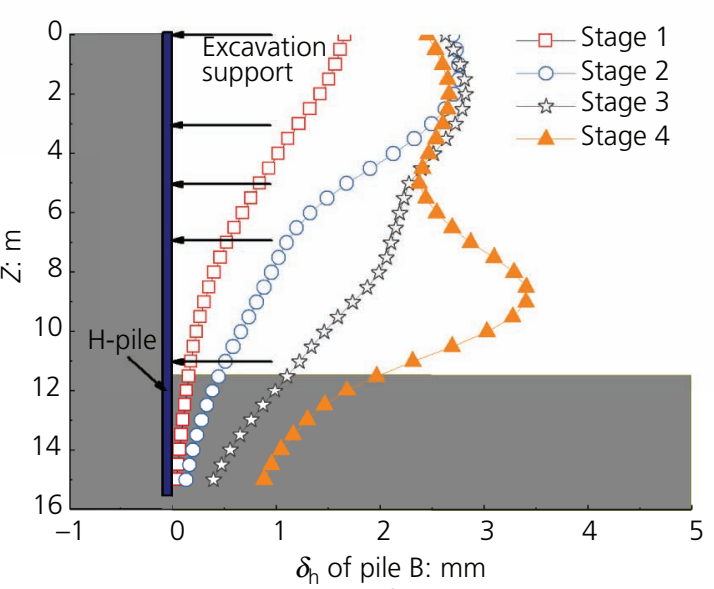

(f)

Figure 10. Numerical analysis outcomes of piles A and B at different excavation stages: (a) von Mises stress of pile $A$; (b) von Mises stress of pile $B$; (c) bending moment $(S M)$ of pile $A$; $(d)$ bending moment of pile $B$; (e) horizontal displacement of pile $A$; ( $f$ ) horizontal displacement of pile $B$

and O'Rourke (1990). Furthermore, Figure 10 proves that the maximum values of the horizontal displacement, von Mises stress and bending moment coincide with each other at the same depth.
Stresses and horizontal displacements of steel panels As an important member of the retaining system, steel panels coordinate with other structural members to restrict the soil 
movement during the excavation of the foundation pit. In practice, the largest deformation in this type of retaining system is the steel panel. In this section, the $\delta_{\mathrm{h}}$ and $\sigma_{\mathrm{M}}$ of steel panels are examined.

Figure 11 presents the contours of von Mises stress and displacement $(U)$ of steel panels. It is found that the magnitudes of $\sigma_{\mathrm{M}}$ and $U$ of the steel panels near the bottom of the foundation pit are obviously larger than the others. This can be partially attributed to the arrangement of waist beams and the overburden pressure at the depth. The $\sigma_{\mathrm{M}}$ and $\delta_{\mathrm{h}}$ of the steel panels at the bottom after completion of excavation stage 4 are shown in Figure 12, where the $X$-axis $R$ stands for the circumference of the working shaft.

It is observed that the maximum $\sigma_{\mathrm{M}}$ values of the steel panels in the $X$ and $Y$ directions are the same in terms of magnitude, which
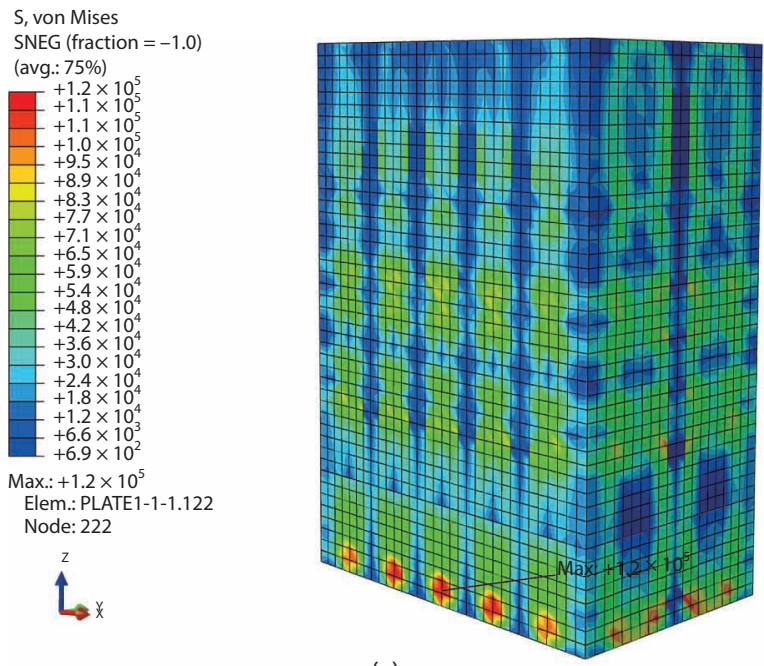

(a)
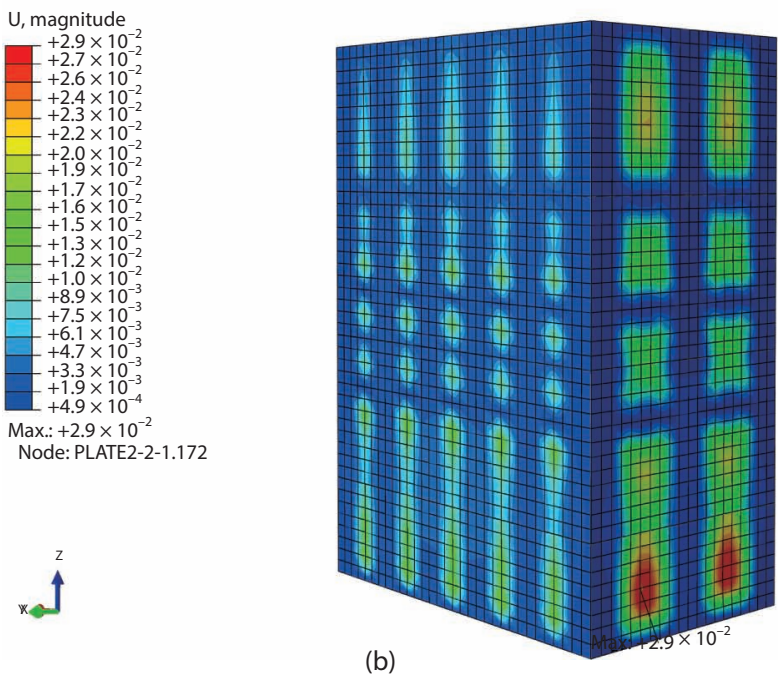

Figure 11. Contours of (a) von Mises stresses (unit: kPa) and (b) deformations of steel panels (unit: $m$ ) is $116 \mathrm{MPa}$. This value is far lower than the design tensile strength of Q235 steel (i.e. $215 \mathrm{MPa}$ ). Nevertheless, the distribution of $\sigma_{\mathrm{M}}$ for the steel panels in the $Y$ direction differs from that of the $X$ direction. This can be explained as being due to the fact that the spacing of the piles is smaller in the $X$ direction, which results in the pile-panel interconnection to act as a whole. In other words, the rigidity of the panel is largely enhanced by connecting to the piles, while in the $Y$ direction, the pile spacing is larger and thus, relatively speaking, the panels act more independently.

The horizontal displacement of the steel panels along the circumference of the shaft is presented in Figure 12(b). As steel panels are connected to the retaining piles using high-strength bolts, steel panels deform in coordination with the retaining piles. As a result, the horizontal displacement of a steel panel from its initial position is $\delta_{\mathrm{i}}=\delta_{\mathrm{p}}+\delta_{\mathrm{p}^{\prime}}$, where $\delta_{\mathrm{p}}$ represents the horizontal displacement of the retaining pile and $\delta_{\mathrm{p}^{\prime}}$ represents the horizontal displacement of the steel panel relative to the deformed pile. Note that both $\delta_{\mathrm{p}}$ and $\delta_{\mathrm{p}^{\prime}}$ are heavily influenced by the lateral earth pressure exerted by the soil behind the panel. As a smaller pile spacing would strengthen the soil arching effects, correspondingly, the lateral earth pressure acting onto the pile and panel would be smaller. This explains the observation of a smaller $\delta_{\mathrm{i}}$ in the $X$ direction - that is, $\delta_{\mathrm{i}}=\delta_{\mathrm{p}}+\delta_{\mathrm{p}^{\prime}}=3.0+13.9=16.9 \mathrm{~mm}-$ and a relatively larger $\delta_{\mathrm{i}}$ in the $Y$ direction - that is, $\delta_{\mathrm{i}}=\delta_{\mathrm{p}}+\delta_{\mathrm{p}^{\prime}}=1.8+$ $26.8=28.6 \mathrm{~mm}$. Lastly, it is noted that the maximum $\delta_{\mathrm{i}}$ values in both the $X$ and $Y$ directions locate at about $10 \mathrm{~m}$ depth.

\section{Analysis of ground settlement}

The ground surface settlement due to foundation pit excavation must be carefully assessed, particularly in urban areas, to avoid causing damage to the adjacent properties. The settlement differs when different retaining systems are used to stabilise the excavation. This part is focused on the quantitative description of the ground surface settlement due to the working shaft excavation and aims to provide some guidance on the development and use of the new prefabricated recyclable retaining system in large deep-foundation-pit projects.

The ground surface settlements of the working shaft are different in $X$ and $Y$ directions, as demonstrated in Figure 13. Intuitively, the displacement of the retaining piles and the ground settlement behind the piles should be highly positively correlated, and it is expected that the larger the horizontal displacement, the larger the ground settlement. However, in this paper, the displacement of piles in the $X$ direction is larger than that of piles in the $Y$ direction, whereas the ground settlement along the $D_{1}$ direction is much less than that along the $D_{2}$ direction. This seems to be counter-intuitive. The reason for this is that the new retaining system under study here consists of both rigid piles and flexible steel panels, and the final ground settlement depends on both structural members. This is one of the main differences between the new supporting system here and many other existing retaining systems where only one structurally reinforcing member is used. For the latter systems, the wall displacement and ground 

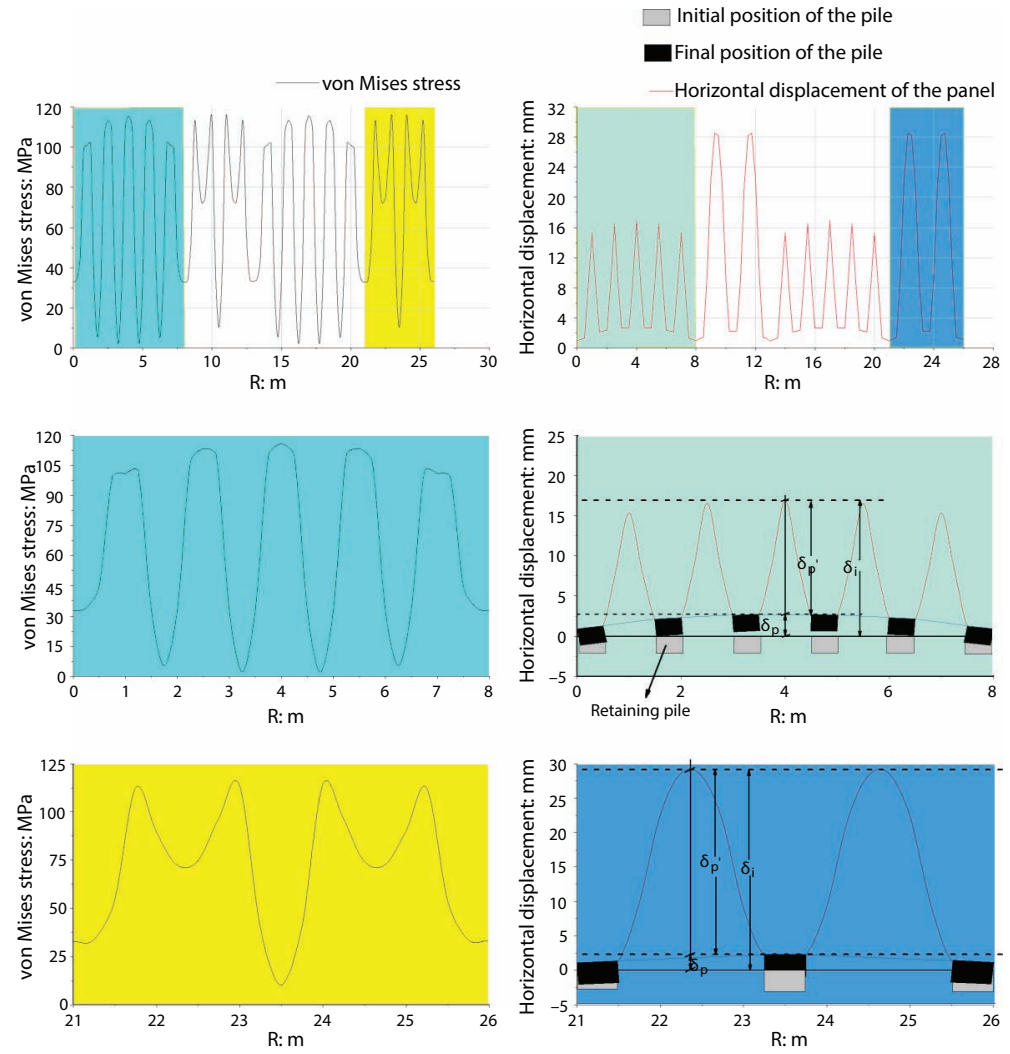

(a)

(b)

Figure 12. von Mises stress and horizontal displacement of steel panels at the bottom of the working shaft: (a) $\sigma_{\mathrm{M}}$ plotted against $R_{\text {; }}$ (b) $\delta_{\mathrm{h}}$ plotted against $R$

settlement are always highly correlated. A further analysis will be provided later.

Figure 13(b) is the enlarged view of the settlement contours profiled from Figure 13(a). The vertical axis $\delta_{\mathrm{v}}$ is the settlement in millimetres. Note that a negative value represents settlement, while a positive value represents heave. The ground surface settlement appears to be a 'vortex' and increases dramatically towards its centre. The maximum settlement is $\delta_{\mathrm{v}}=7.3 \mathrm{~mm}$ in the centre of the vortex.

Figures 14(a) and 14(b) are the ground surface settlements with respect to different excavation stages. The horizontal coordinates ' $D_{1}$ ' and ' $D_{2}$ ' represent the distances from the shaft wall to the outer boundary of the model, and $\Delta \delta_{1}, \Delta \delta_{2}, \Delta \delta_{3}$ and $\Delta \delta_{4}$ are the increments between successive excavation stages. Obviously and as expected, the maximum $\delta_{\mathrm{v}}$ occurs in the steel panel zone, other than the H-pile zone. This is simply because the steel panels deform laterally much more than the piles.

Two more differences can be observed between the ground settlements along the $D_{1}$ and $D_{2}$ directions. Along $D_{1}$, shown in Figure $14(\mathrm{a}), \delta_{\mathrm{v}}$ reaches $\Delta \delta_{1}=2.6 \mathrm{~mm}$ and $\Delta \delta_{1}+\Delta \delta_{2}+\Delta \delta_{3}+$ $\Delta \delta_{4}=4.5 \mathrm{~mm}$ at completions of the first and last stages of excavation, respectively. This means that after excavation stage 1 , $\delta_{\mathrm{v}}$ continues to increase significantly as excavation proceeds. However, along $D_{2}$, shown in Figure 14(b), $\delta_{\mathrm{v}}$ increases insignificantly from $\Delta \delta_{1}=6.2 \mathrm{~mm}$ at completion of excavation stage 1 to $\Delta \delta_{1}+\Delta \delta_{2}+\Delta \delta_{3}+\Delta \delta_{4}=7.3 \mathrm{~mm}$ at completion of excavation stage 4 . The second difference is that the maximum $\delta_{\mathrm{v}}$ along $D_{1}$ appears to move away from the wall as excavation proceeds - that is, from stages 1 to 4 , the maximum $\delta_{\mathrm{v}}$ moves about $0.7 \mathrm{~m}$ away from the wall - whereas for the maximum $\delta_{\mathrm{v}}$ along $D_{2}$, it appears to stay about $0.65 \mathrm{~m}$ from the wall, regardless of excavation stages. The maximum $\delta_{\mathrm{v}}$ of $7.3 \mathrm{~mm}$ is far less than the alarm value set for the project. The alarm values are provided in Table 3 according to GB 50497-2009 (SAC, 2009). The differences of the primary influence zones between the first and final stages of excavation on ground settlement are about $11 \mathrm{~m}$ in $D_{1}$ and $5.5 \mathrm{~m}$ in $D_{2}$. With the working shaft excavation, the influence range of ground surface settlement exhibits a growing trend.

\section{Influence of pile embedded depth and panel thickness}

Horizontal displacement $\left(\delta_{h}\right)$ against EDR

The plots of horizontal displacement $\left(\delta_{\mathrm{h}}\right)$ of pile $\mathrm{A}$ and pile $\mathrm{B}$ along the depth with respect to different EDRs are shown in 
Geotechnical Research

Volume 7 Issue 3
Numerical analyses of a prefabricated retaining system for foundation pits in silt soils

Guo, Wang, Lin and Wang

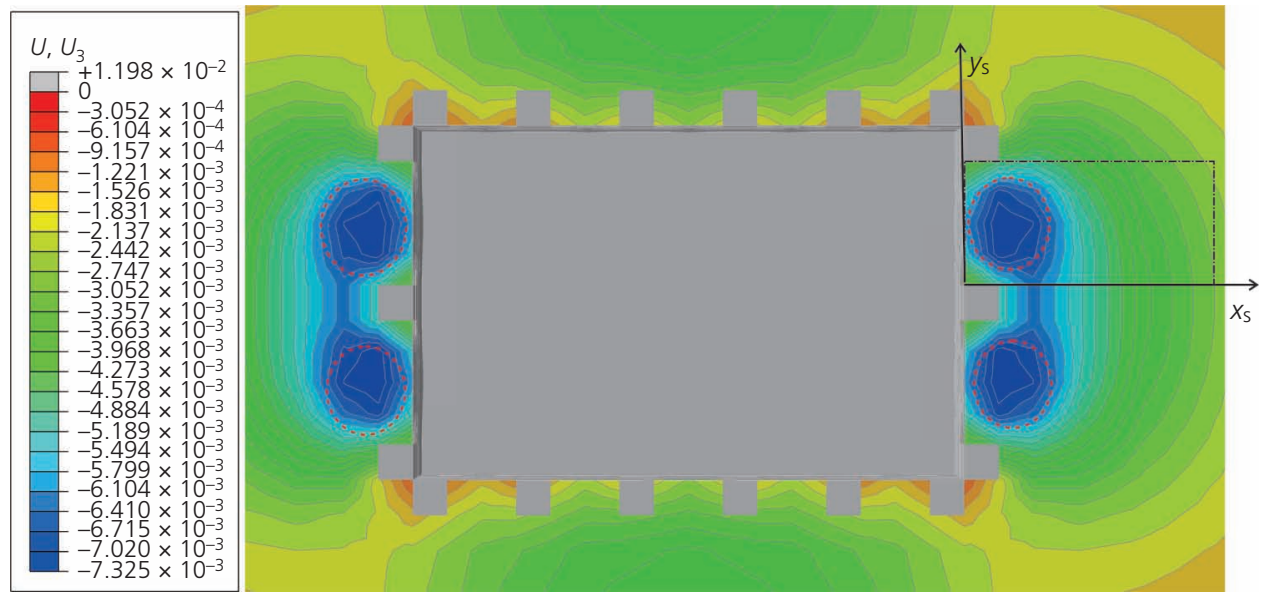

(a)

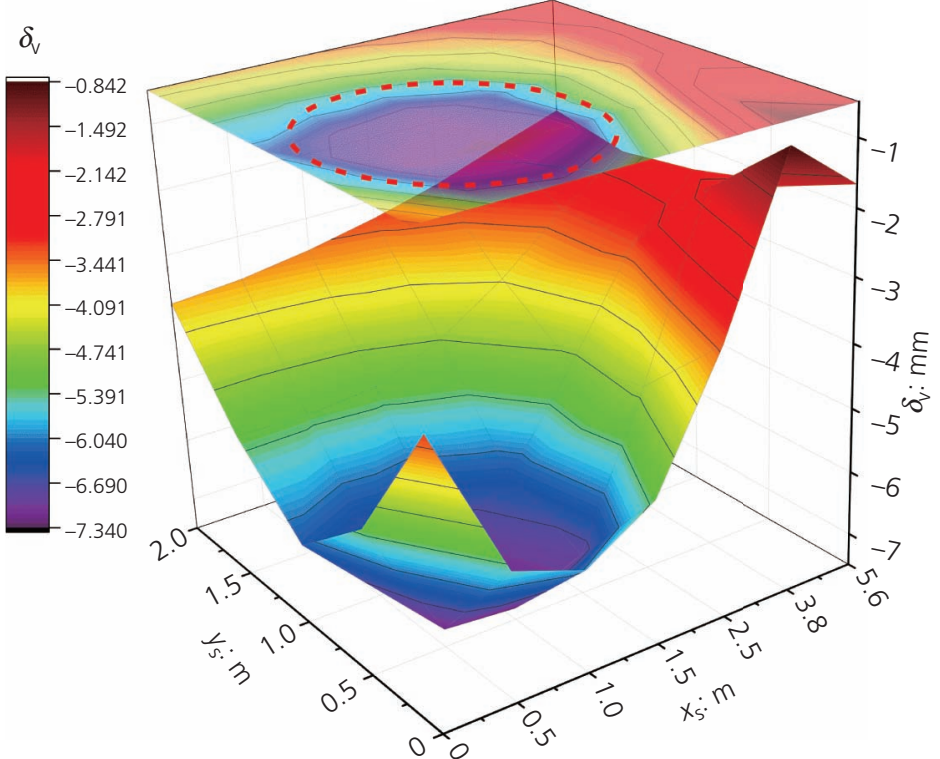

(b)

Figure 13. Contours of ground surface settlement: (a) entire view of $\delta_{\mathrm{h}}$; (b) enlarged view of $\delta_{\mathrm{h}}$
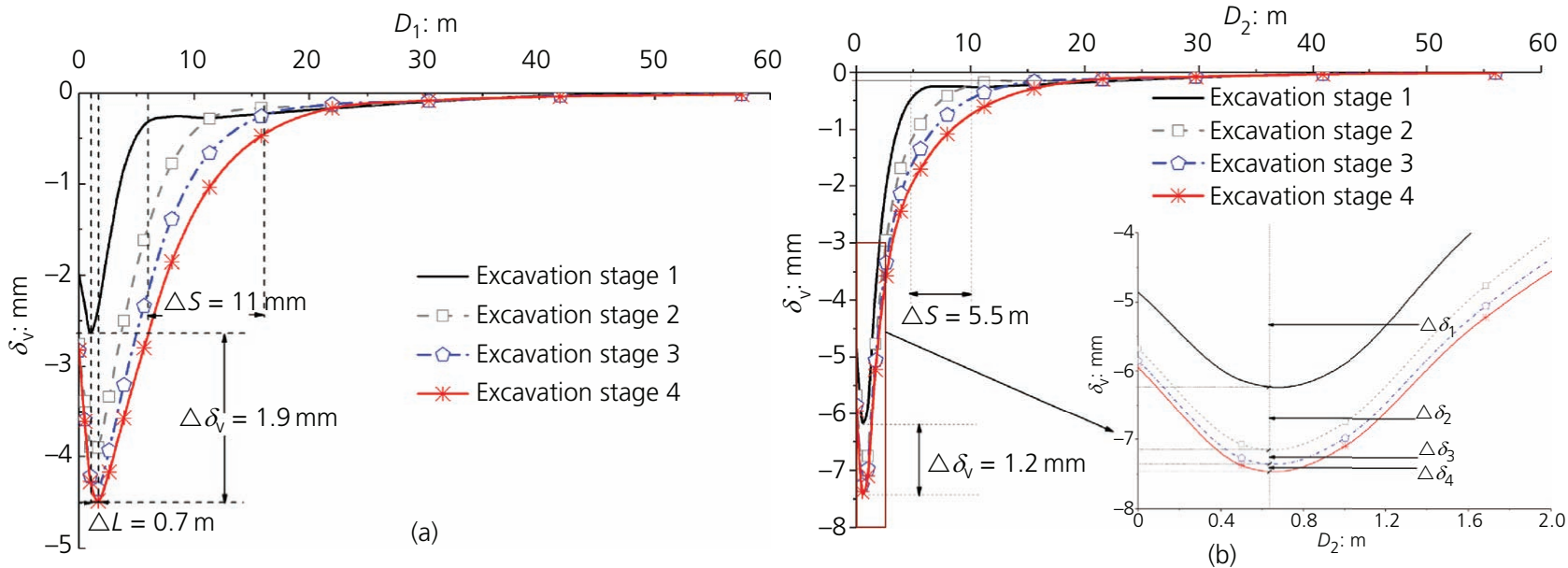

Figure 14. Ground surface settlements along the $D_{1}$ and $D_{2}$ directions: (a) $\delta_{\mathrm{h}}$ along $D_{1} ;$ (b) $\delta_{\mathrm{h}}$ along $D_{2}$ 
Table 3. Alarm values set for the case history

\begin{tabular}{lcc} 
Monitoring programme & \multicolumn{2}{c}{ Level I } \\
\cline { 2 - 3 } $\begin{array}{l}\text { Monitoring level of the } \\
\text { foundation pit }\end{array}$ & $\begin{array}{c}\text { Rate of } \\
\text { change: } \\
\text { mm/d }\end{array}$ & $\begin{array}{l}\text { Cumulative } \\
\text { value: } \mathrm{mm}\end{array}$ \\
\hline Horizontal displacement of the slope & 3 & 25 \\
Vertical displacement of the ground & 3 & 25 \\
Displacement of deep soil & 3 & 25 \\
\hline
\end{tabular}

Figures 15(a) and 15(b). In this case study, $\delta_{\mathrm{h}}$ appears to be little influenced by the EDR. This is reasonable, as the prefabricated retaining system in this study is largely overdesigned. However, it should be noted that this may not be the case if other types of retaining systems are used (e.g. Liu and Hou, 1998). Figure 15(c) plots the maximum $\delta_{\mathrm{h}}$ (denoted as $\delta_{\mathrm{hm}}$ ) against EDR for piles A and $\mathrm{B}$. While the maximum $\delta_{\mathrm{h}}$ decreases with increasing EDR, the difference is very small - that is, $\Delta \delta_{\mathrm{hm}}=0.1 \mathrm{~mm}$. Figure $15(\mathrm{~d})$ regresses the normalised $\delta_{\mathrm{hm}} / H_{\mathrm{e}}$ against the EDR using a firstorder polynomial, where $H_{\mathrm{e}}$ is the pile embedded depth calculated from the bottom surface of the shaft. As seen, $\delta_{\mathrm{hm}} / H_{\mathrm{e}}$ slightly decreases as the EDR increases. Previous research studies (Clough et al., 1989; Long, 2001) suggested that $\delta_{\mathrm{hm}} / H_{\mathrm{e}}$ decreases with increasing stiffness of the support system. The new retaining system investigated here is a composite structure with both rigid and flexible structural members. The retaining pile, as a rigid element, has a good overall stability. Thus, on the basis of strong stiffness, the EDR had little effect on the deformation of the retaining pile.

$\delta_{\mathrm{hm}}$ and $\sigma_{\mathrm{M}}$ against thickness of steel panels $(T)$

As an important flexible member in the retaining system, the thickness of the steel panel (denoted as $T$ ) would not only affect its own deformation but also affect the $\delta_{\mathrm{hm}}$ of the piles and the ground settlement. In this section, FE models are rebuilt with $T=$ $2.5,5.0,7.5,10.0,12.5$ and $15.0 \mathrm{~mm}$ to examine the effect of steel panel thickness on the displacements of steel panels, retaining piles and the ground surface.

The plots of $\delta_{\mathrm{hm}}$ against $T$ and $\sigma_{\mathrm{M}}$ against $T$ are shown in Figures 16(a) and 16 (b), respectively. In the figures, $k_{\delta}$ and $k_{\sigma}$ represent the slopes of the $\delta_{\mathrm{hm}}$ and $\sigma_{\mathrm{M}}$ curves, with negative values representing a decreasing trend. As $T$ increases from 2.5 to $15.0 \mathrm{~mm}$, correspondingly the $\delta_{\mathrm{hm}}$ of the steel panels reduces remarkably from 32.0 to $5.6 \mathrm{~mm}$ and the maximum $\sigma_{\mathrm{M}}$ of the steel panels reduces significantly from 123 to $73.6 \mathrm{MPa}$. In addition, it is found from $k_{\delta}$ and $k_{\sigma}$ that $T$ is impactful on the $\delta_{\mathrm{hm}}$ and $\sigma_{\mathrm{M}}$ of steel panels but has little effect on the $\delta_{\mathrm{hm}}$ and $\sigma_{\mathrm{M}}$ of retaining piles.

Figure 17 presents the ground surface settlement of excavation stage 4 plotted against different thicknesses of steel panels $(T)$. Along the $D_{1}$ and $D_{2}$ directions, as $T$ increases, the ground settlement tends to decrease largely. When $T$ reaches $12.5 \mathrm{~mm}$ and
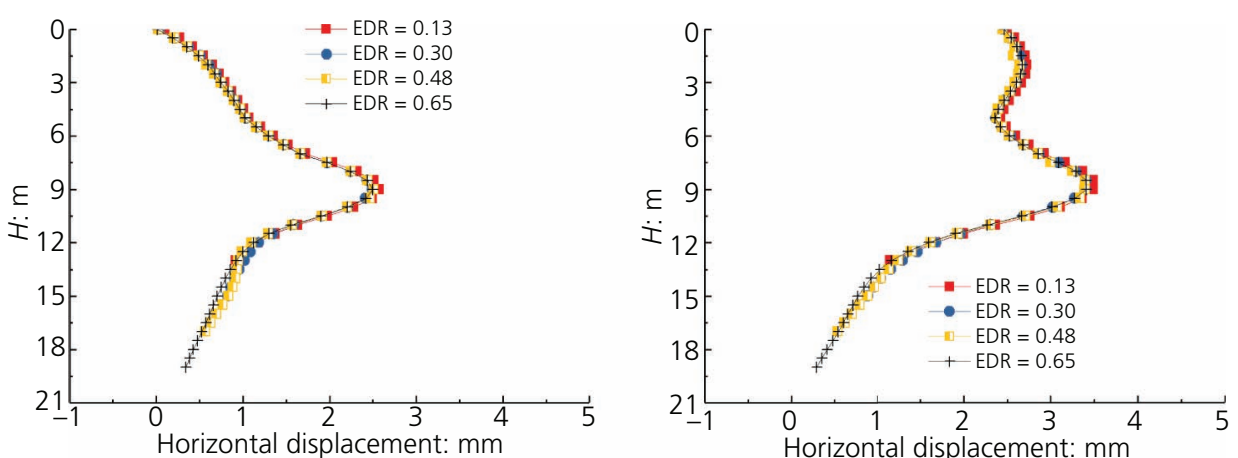

(a)

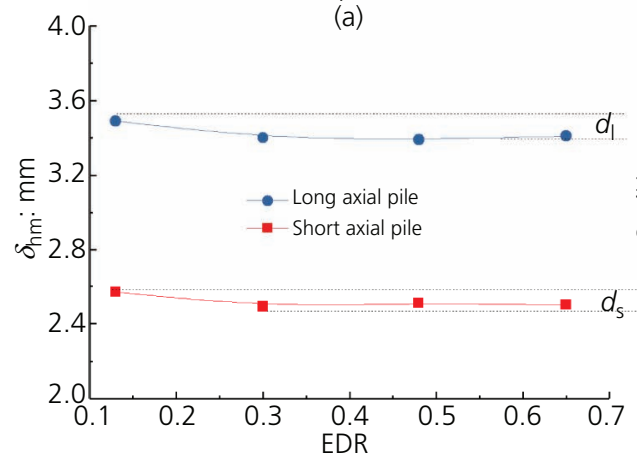

(c)

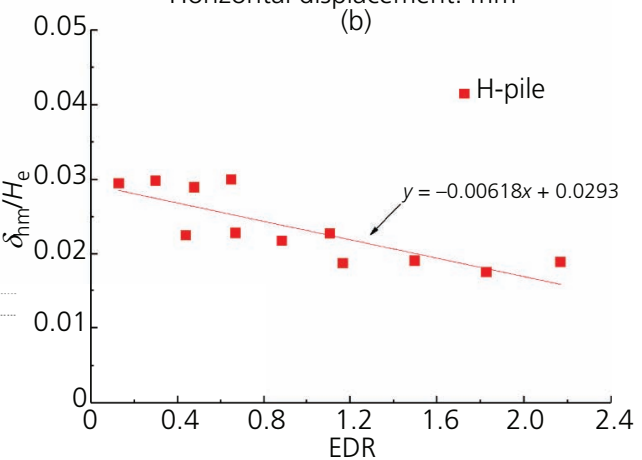

(d)

Figure 15. Influences of EDR on horizontal displacement of the retaining piles: (a) $\delta_{\mathrm{h}}$ of pile A; (b) $\delta_{\mathrm{h}}$ of pile B; (c) $\delta_{\mathrm{hm}}$ of long axial pile and short axial pile; (d) $\delta_{\mathrm{hm}} / H_{\mathrm{e}}$ 


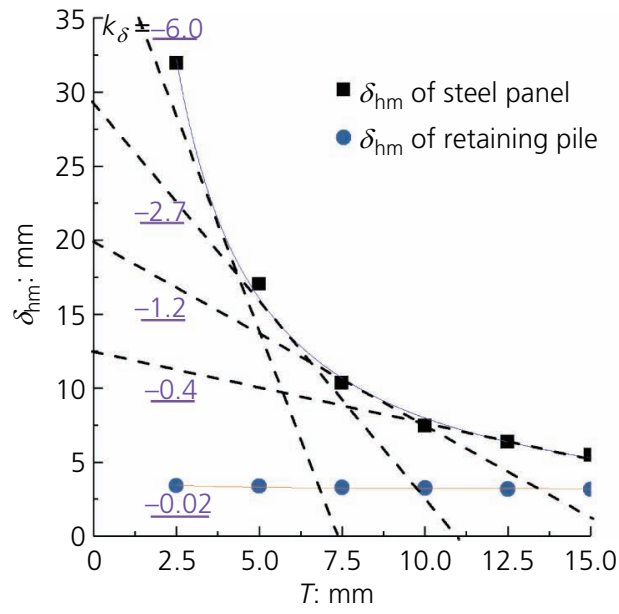

(a)

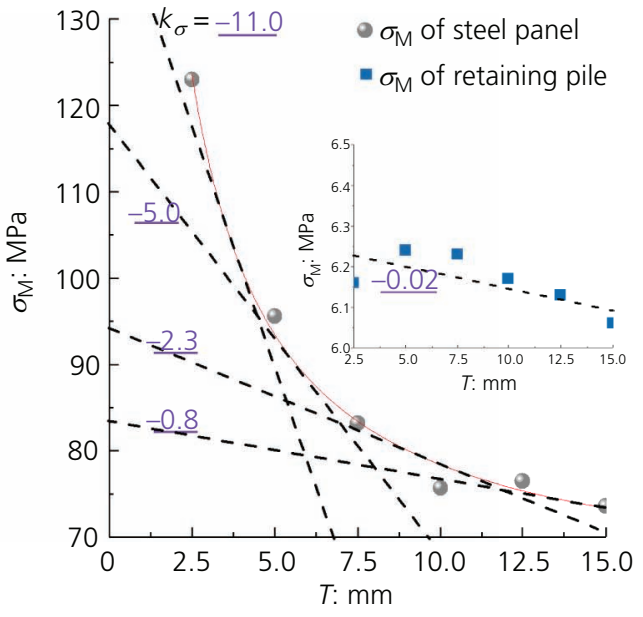

(b)

Figure 16. Influences of the thickness of steel panels on the development of the maximum horizontal displacement and von Mises stress: (a) $\delta_{\mathrm{hm}}$ of the panels and piles; (b) maximum $\sigma_{\mathrm{M}}$ of panels

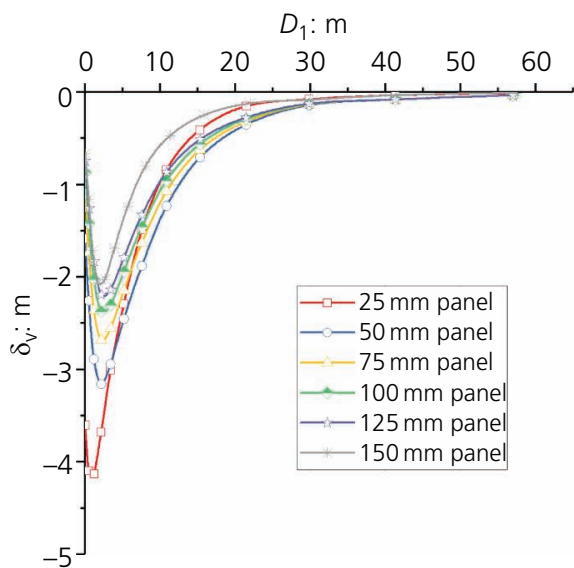

(a)

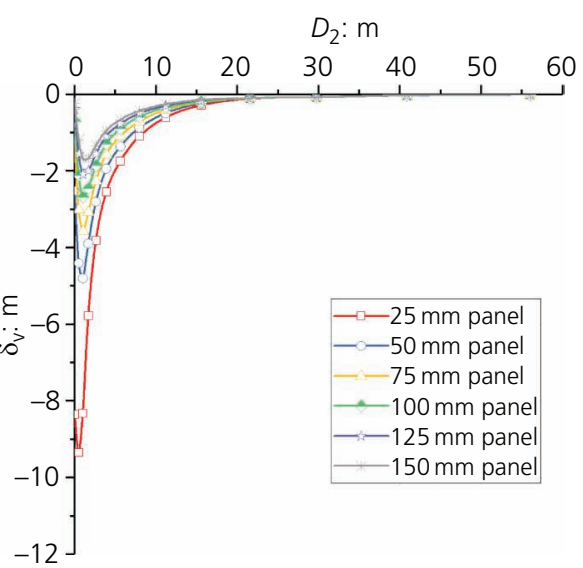

(b)

Figure 17. Ground settlements along the (a) $D_{1}$ and (b) $D_{2}$ directions given different thicknesses of steel panels

beyond, the ground settlements become practically the same for $D_{1}$ and $D_{2}$; both are around $2.2 \mathrm{~mm}$. Case histories compiled by Hsieh and Ou (1998) showed that the maximum settlement of the ground surface $\left(\delta_{\mathrm{vm}}\right)$ is statistically related to the maximum wall deflection $\left(\delta_{\mathrm{hm}}\right)$. As the present retaining system includes both retaining piles and steel panels, $\delta_{\mathrm{v}}$ depends on the $\delta_{\mathrm{hm}}$ of retaining piles and steel panels. From this analysis, the authors conclude that selection of the thickness of the steel panels is crucial to the new retaining system and must be carefully addressed in design.

As shown in Figure 18, the empirical curve of the settlement profile compiled by Hsieh and Ou (1998) shows that the settlement is equal to $0.1 \delta_{\mathrm{vm}}$ at $2 H_{\mathrm{e}}$ and is practically negligible at $4 H_{\mathrm{e}}$. Note that $H_{\mathrm{e}}$ is the final excavation depth of the foundation pit. In this study, the curve of the settlement profile is slightly different from the one proposed by Hsieh and Ou (1998). The positions of $0.1 \delta_{\mathrm{vm}}$ (point B) are all less than $2 H_{\mathrm{e}}$ but also practically negligible at $4 H_{\mathrm{e}}$ (point $\mathrm{C}$ ). This is due to the fact that during different excavations, strut installation procedures and retaining structures result in different stress states for the soil near the wall, which may in turn yield different shapes of the settlement profile. In addition, since steel panels are important flexible members in the retaining system, the local soil behind the steel panels would settle in a vortex shape, which makes the primary influence zone obtained by the empirical method less than $2 H_{\mathrm{e}}$. According to the principle of Saint-Venant (Timonshenko and Goodier, 1951), different excavations, strut installation procedures and retaining structures might have little influence on the state of stress for soil far away from the wall. This explains the practical ignorance of $\delta_{\mathrm{h}} / \delta_{\mathrm{hm}}$ at $4 H_{\mathrm{e}}$ (point C), which is the same as the point proposed by Hsieh and $\mathrm{Ou}$ (1998). Moreover, it is found that as the thickness of the steel panel increases, the primary influence 


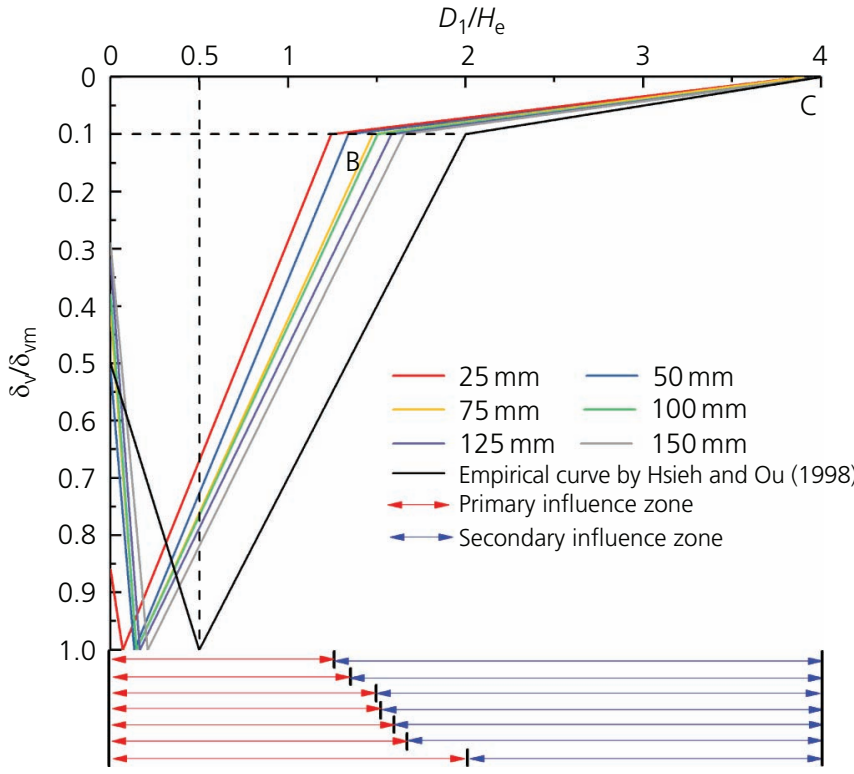

(a)

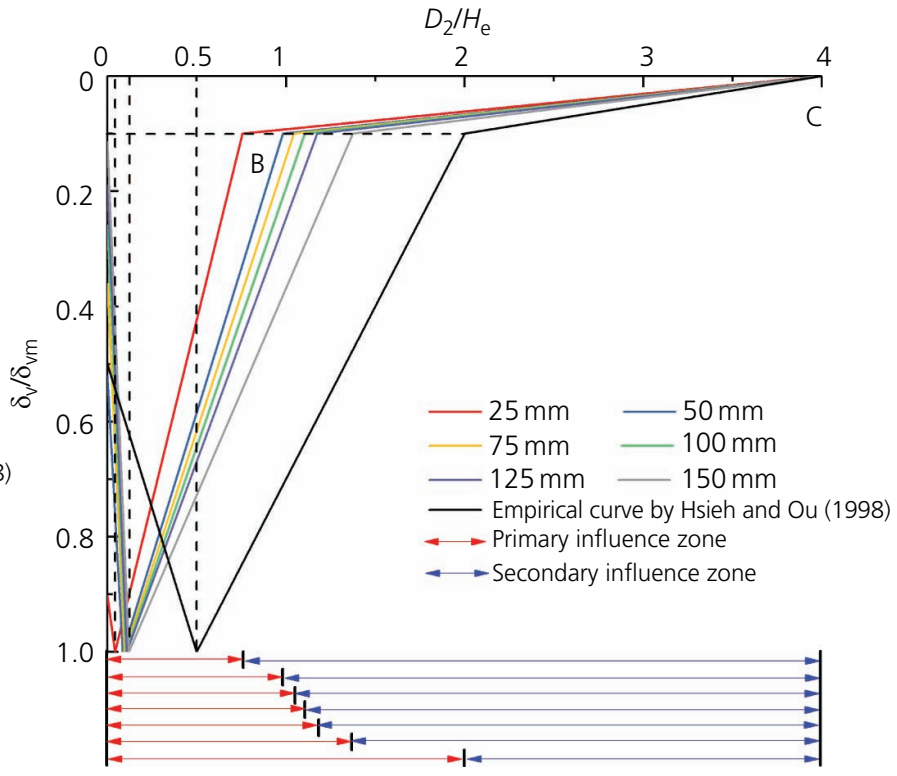

(b)

Figure 18. Settlement profiles of the new retaining system assuming different steel panel thicknesses: (a) $\delta / \delta_{\mathrm{vm}}$ along $D_{1} ;$ (b) $\delta / \delta_{\mathrm{m}}$ along $D_{2}$

zone of the retaining system gradually moves towards the zone proposed by Hsieh and $\mathrm{Ou}$ (1998). This can be interpreted as follows: with the increase in the thickness of the steel panels, the lateral displacement gradually decreases, resulting in the reduction in the settlement vortex of the ground surface behind the steel panels; correspondingly, the lateral displacement of retaining piles and steel panels in the new retaining system changes from two orders of magnitude of difference to the same order.

Figure 19 shows the plots of the maximum displacement of the steel panels and the ground settlement against the thickness of the steel panels. When the thickness $T$ is small (e.g. $2.5-7.5 \mathrm{~mm}$ in Figure 19), the deformation of the steel panel and the settlement decrease quickly with increasing $T$. When the thickness reaches beyond a certain value (e.g. $10.0 \mathrm{~mm}$ ), the decreasing trend gradually becomes flat. However, this variation has certain numerical differences between the $X$ and $Y$ directions, due to the effect of the spacing of the retaining piles and the size of the foundation pit on the displacement of the steel panel.

The preceding analyses demonstrate that due to the difference in material and dimensions between the assembled parts of the new recyclable retaining system, the influence on the settlement of the $D_{1}$ and $D_{2}$ directions of the foundation pit could not be ignored. It is highly important to select a reasonable steel panel type and a reasonable pile interval to protect adjacent properties. Furthermore, the analysis outcomes are crucial for the use of the retaining structure in subsequent large deep foundation pits.
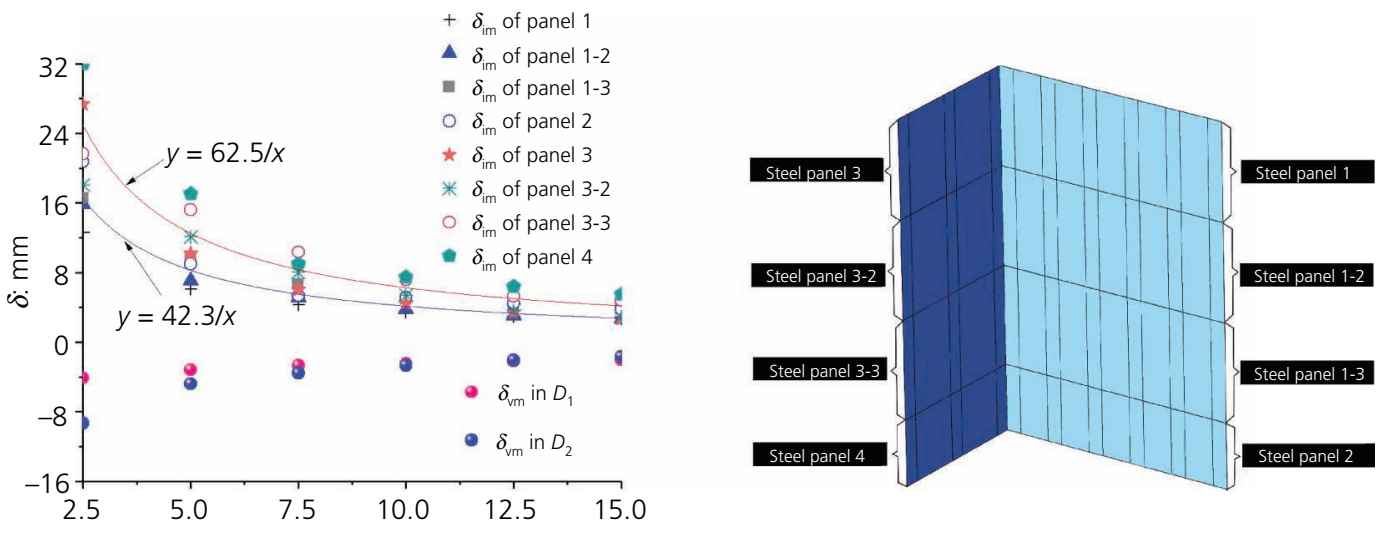

Figure 19. Influences of the thickness of steel panels on the deformation of the steel panels and the ground surface settlement: (a) the $\delta$ of steel panels and ground surface; (b) classification of steel panels 


\section{Conclusions}

This paper presents numerical analyses of a new prefabricated recyclable retaining system used for a working shaft excavated in silts for a pipe-jacking project in Northern China. A 3D numerical model is built in Abaqus to carry out the analyses. The model is first validated by comparing its analysis outcomes against field monitoring data. After validation, the model is further used to investigate the stresses and deformations of the main structural members of the new retaining system, including the H-piles and steel panels. In addition, the ground surface settlement is also studied. The main conclusions drawn from this study are as the following.

- Typically, the maximum von Mises stress, maximum bending moment and maximum horizontal displacement that the steel H-piles sustain in such a retaining system are far less than the allowable values in design. The positions of the aforementioned three maximum quantities move downwards with increasing excavation depth and finally stay at the same depth.

- The maximum horizontal displacement of the piles in the system is basically about $3.0 \mathrm{~mm}$, which is much less than that of similar structural members in many other traditional retaining systems. For the steel panels, the maximum horizontal displacement is roughly an order of magnitude higher than that of the H-piles.

v The ground settlement near the foundation pit depends on the pit size and the type of the retaining system. The ground settlement is significantly influenced by the deformation of the steel panels. With the increase in the steel panel thickness, the maximum ground settlement as well as the maximum deformation of the steel panels will be remarkably reduced. It is suggested that the thickness of steel panels should not be less than $3.0 \mathrm{~mm}$.

- The new prefabricated recyclable retaining system has the advantages of safety, fast construction, recyclable utilisation and low cost (long-term, on average). In addition, it has great potential in the stabilisation of large deep foundation pits.

\section{Acknowledgements}

The authors are grateful for financial support from the Henan Major Science \& Technology Projects (181100310400) granted to the first author and the Young Scholar Research Fund (76140-18841225) by Sun Yat-Sen University granted to the corresponding author.

\section{REFERENCES}

Arnold M, Beckhaus K and Wiedenmann U (2011) Cut-off wall construction using Cutter Soil Mixing: a case study. Geotechnik 34(1) 11-21, https://doi.org/10.1002/gete.201000021.

Bella G, Barbero M, Barpi F, Borri-Brunetto M and Peila D (2017) An innovative bio-engineering retaining structure for supporting unstable soil. Journal of Rock Mechanics and Geotechnical Engineering 9(2): 247-259, https://doi.org/10.1016/j.jrmge.2016.12.002.

Belytschko T, Krongauz Y, Organ D, Fleming M and Krysl P (1996) Meshless methods: an overview and recent developments. Computer Methods in Applied Mechanics and Engineering 139(1-4): 3-47, https://doi.org/10.1016/S0045-7825(96)01078-X.
Bilgin O (2012) Lateral earth pressure coefficients for anchored sheet pile walls. International Journal of Geomechanics 12(5): 584-595, https:doi.org/10.1021/ie202717m.

Chambers P, Augarde C, Reed S and Dobbins A (2016) Temporary propping at Crossrail Paddington station. Geotechnical Research 3(3): 3-16, https://doi.org/10.1680/jgere.15.00009.

Chen WF and Sarip AF (2005) Elasticity and Plasticity. China Architecture \& Building Press, Beijing, China.

Clough GW and O'Rourke TD (1990) Construction induced movements of in situ walls. In Design and Performance of Earth Retaining Structures (Lambe P (ed.)). American Society of Civil Engineers, New York, NY, USA, GSP 25, pp. 439-470.

Clough GW, Smith EM and Sweeney BP (1989) Movement control of excavation support systems by iterative design. In Foundation Engineering: Current Principles and Practices (Kulhawy FH (ed.)). American Society of Civil Engineers, New York, NY, USA, GSP 22, pp. 869-884.

Crawford RJ and Byfield MP (2002) A numerical model for predicting the bending strength of Larssen steel sheet piles. Journal of Constructional Steel Research 58(10): 1361-1374, https://doi.org/ 10.1016/s0143-974x(02)00016-0.

Du H (2017) Research on Influence of Foundation Pit Excavation on Subway Tunnel Deformation in Silt Area. Master's thesis, Zhengzhou University, Zhengzhou, China (in Chinese).

Faustin NE, Elshafie MZEB and Mair RJ (2018) Case studies of circular shaft construction in London. Proceedings of the Institution of Civil Engineers - Geotechnical Engineering 171(5): 391-404, https://doi. org/10.1680/jgeen.17.00166.

Ferziger JH and Peric M (2002) Computational Methods for Fluid Dynamics. Springer, Berlin, Germany.

Gao CL, Zhou ZQ, Yang WM et al. (2019) Model test and numerical simulation research of water leakage in operating tunnels passing through intersecting faults. Tunnelling and Underground Space Technology 94: 103-134, https://doi.org/10.1016/j.tust.2019.103134.

Goh ATC, Zhang F, Zhang WG, Zhang YM and Liu HL (2017) A simple estimation model for 3D braced excavation wall deflection. Computers and Geotechnics 83: 106-113, https://doi.org/10.1016/j.compgeo. 2016.10.022.

Grande L (1998) Some aspects on sheet pile wall analysis. In International Conference on Soil Structure Interaction in Urban Civil Engineering (Festag G (ed.)). Institute and Laboratory of Geotechnics, Darmstadt University of Technology, Darmstadt, Germany, pp. 193-211.

Hsieh PG and Ou CY (1998) Shape of ground surface settlement profiles caused by excavation. Canadian Geotechnical Journal 35(6): 1004-1017, https://doi.org/10.1139/cgj-35-6-1004.

Ju M, Li X, Yao Q et al. (2017) Effect of sand grain size on simulated mining-induced overburden failure in physical model tests. Engineering Geology 226: 93-106, https://doi.org/10.1016/j.enggeo. 2017.05 .015$.

Lam AKM (2018) An engineering solution for a hillside project in Hong Kong. Geotechnical Research 5(3): 170-181, https://doi.org/10.1680/ jgere.18.00008.

Latapie B, Winarta T and Lloyd SD (2017) Benefits of pre-loading temporary props for braced excavations. Geotechnical Research 4(3): 178-191, https://doi.org/10.1680/jgere.17.00011.

Li S and Liu WK (2002) Meshfree and particle methods and their applications. Applied Mechanics Reviews 55(1): 1-34, https://doi.org/ $10.1115 / 1.1431547$

Li L, Chen D, Li S et al. (2017) Numerical analysis and fluid-solid coupling model test of filling-type fracture water inrush and mud gush. Geomechanics and Engineering 13(6): 1011-1025, https://oi.org/ 10.12989/gae.2017.13.6.1011.

Li W, Zhang Q, Liu R et al. (2019) Quality evaluation and applicability analysis of TRD method in sand stratum of subway station. 
Geotechnical and Geological Engineering 37(4): 3013-3023, https:// doi.org/10.1007/s10706-019-00820-5.

Likitlersuang S, Surarak C, Suwansawat S et al. (2014) Simplified finiteelement modelling for tunnelling-induced settlements. Geotechnical Research 1(1): 133-152, https://doi.org/10.1680/gr.14.00016.

Liu J and Hou X (1998) Excavation Engineering Handbook. China Architecture \& Building Press, Beijing, China (in Chinese).

Long M (2001) Database for retaining wall and ground movements due to deep excavations. Journal of Geotechnical and Geoenvironmental Engineering 127(3): 203-224, https://doi.org/10.1061/(asce)1090-0241 (2001)127:3(203).

Oliveira HL, Chateauneuf A and Leonel ED (2019) Probabilistic mechanical modelling of concrete creep based on the boundary element method. Advances in Structural Engineering 22(2): 337-348, https://doi.org/10.1177/1369433218788088.

Osthoff D and Grabe J (2018) Deformational behaviour of steel sheet piles during jacking. Computers and Geotechnics 101: 1-10 https://doi.org/10.1016/j.compgeo.2018.04.014.

Pan Y, Fang H, Li B and Wang F (2019) Stability analysis and full-scale test of a new recyclable supporting structure for underground ecological granaries. Engineering Structures 192: 205-219, https://doi. org/10.1016/j.engstruct.2019.04.087.

Potts DM and Zdravkovic L (2001) Finite Element Analysis in Geotechnical Engineering: Application. Thomas Telford, London, UK.

Qiu H, Kong J and Wang R (2016) Dynamic active earth pressures of the retaining piles with anchors under vehicle loads. Shock and Vibration 2016: article 4023827, https://doi.org/10.1155/2016/4023827.

Rabbani P, Tolooiyan A, Lajevardi SH, Daghigh Y and Falah M (2019) The effect of the depth of cutter soil mixing on the compressive behavior of soft clay treated by alkali-activated slag. KSCE Journal of Civil Engineering 23(10): 4237-4249, https://doi.org/10.1007/s12205019-0335-4.

SAC (Standardization Administration of China) (2009) GB 50497-2009: Technical code for monitoring of building foundation pit engineering. China Architecture \& Building Press, Beijing, China (in Chinese).

SAC (2017) GB 50017-2017: Standard for design of steel structures. China Architecture \& Building Press, Beijing, China (in Chinese)

Sun Y, Su J, Xia X and Xu Z (2015) Numerical analysis of soil deformation behind the reaction wall of an open caisson induced by horizontal parallel pipe-jacking construction. Canadian Geotechnical Journal 52(12): 2008-2016, https://doi.org/10.1139/cgj-2015-0024.

Timonshenko SP and Goodier JN (1951) Theory of Elasticity. McGrawHill, New York, NY, USA.

Tran VDH, Meguid MA and Chouinard LE (2015) Three-dimensional analysis of geogrid-reinforced soil using a finite-discrete element framework. International Journal of Geomechanics 15(4): article 04014066, https://doi.org/10.1061/(ASCE)GM.1943-5622.0000410.

Wang F, Shi M, Zhang B and Guo C (2013) Grouting method of polymer for vertical support system. Chinese Patent CN103215960A (in Chinese).

Wang C, Guan C and Yang Y (2015) Rapid excavation with a newly developed retaining system: spiral assembly steel structure. Journal of
Central South University 22(7): 2719-2729, https://doi.org/10.1007/ s11771-015-2802-5.

Wang W, Xu Z and Li Q (2018a) Design and construction of deep excavations in Shanghai, China. Geotechnical Research 5(3): 143-161, https://doi.org/10.1680/jgere.18.00007.

Wang F, Fang H, Pan Y and Zhao P (2018b) Design and construction method of flexible prefabricated recoverable rectangular working shaft support structure. Chinese Patent CN109056746A (in Chinese).

Wang F, Fang H, Pan Y and Zhao P (2019a) Design and construction method of flexible prefabricated recoverable row piles support structure. Chinese Patent CN109295985A (in Chinese).

Wang F, Pan Y and Zhao P (2019b) Design and construction method of flexible anti seepage prefabricated recoverable row piles support structure with rectangular section. Chinese Patent CN107190752B (in Chinese).

Wang F, Pan Y and Zhao P (2019c) Design and construction method of flexible anti seepage prefabricated recoverable row piles support structure with circular section. Chinese Patent CN107130611B (in Chinese).

Wu G, Jia S, Chen W, Yang J and Yuan J (2018) Modelling analysis of the influence of shield crossing on deformation and force in a large diaphragm wall. Tunnelling and Underground Space Technology 72: 154-161, https://doi.org/10.1016/j.tust.2017.11.028.

Xie JR, Li BT, Chen PH and Zhuang YQ (2014) Optimized design of Larsen steel sheet pile supporting structure based on parameter sensitivity. Applied Mechanics and Materials 501-504: 770-776, https://doi.org/ 10.4028/www.scientific.net/AMM.501-504.770.

Zhang WG, Goh ATC and Xuan F (2015) A simple prediction model for wall deflection caused by braced excavation in clays. Computers and Geotechnics 63: 67-72, https://doi.org/10.1016/j.compgeo.2014.09. 001

Zhang P, Ma B, Zeng C et al. (2016) Key techniques for the largest curved pipe jacking roof to date: a case study of Gongbei tunnel. Tunnelling and Underground Space Technology 59: 134-145, https://doi.org/ 10.1016/j.tust.2016.07.001.

Zhang MX, Xu P, Li JW and Wang RQ (2019) Mining-induced ground movements and displacements using transparent soil model test. Geotechnical Research 6(4): 252-264, https://doi.org/10.1680/jgere. 18.00031 .

Zhang WG, Han L, Chen Z et al. (2020a) Model tests on seismic performance of double-box underground utility tunnel. Chinese Journal of Geotechnical Engineering 42(1): 100-108, https://doi.org/ 10.11779/CJGE202001011.

Zhang W, Li Y, Goh ATC and Zhang R (2020b) Numerical study of the performance of jet grout piles for braced excavations in soft clay. Computers and Geotechnics 124: article 103631, https://doi.org/ 10.1016/j.compgeo.2020.103631.

Zhao G, Meng S, Guan C and Yang Y (2019) Test study on the stress and deformation behaviors of a shaft supported by a prefabricated prestressed structure. Applied Sciences 9(4): article 629, https://doi.org/ 10.3390/app9040629.

Zheng G, Zeng CF, Diao Y and Xue XL (2014) Test and numerical research on wall deflections induced by pre-excavation dewatering. Computers and Geotechnics 62: 244-256, https://doi.org/10.1016/j.compgeo. 2014.08.005.

\section{How can you contribute?}

To discuss this paper, please submit up to 500 words to the editor at journals@ice.org.uk. Your contribution will be forwarded to the author(s) for a reply and, if considered appropriate by the editorial board, it will be published as a discussion in a future issue of the journal. 